\title{
Molecular Mechanisms in Synaptic Plasticity
}

\author{
M. Mayadevi*, G.M. Archana*, \\ Ramya R. Prabhu* and R.V. Omkumar \\ Molecular Neurobiology Division, \\ Rajiv Gandhi Centre for Biotechnology, Thycaud, Kerala, \\ India
}

\section{Introduction}

Brain is a sophisticated information processing and storage system with capabilities unmatched by any manmade computers. Neurons, the primary building blocks of the brain are structurally and functionally specialized to do these functions. The neuronal membrane is equipped with several types of ion channel and ion pump proteins which enable it to conduct nerve impulses in the form of electrochemical signals called action potentials. The highly branched structure of the neuron with dendrites and axons helps in not only transmitting these signals but also in information processing by integrating multiple inputs. Storage of information, on the other hand, happens by permanent changes in the brain consequent to activity that will serve the function of recording information input. This remarkable property of the brain is known as plasticity and brings about changes in the structures and functions of the brain in response to internal and external stimuli. Plasticity can be defined as the ability of neural circuitry to undergo modifications consequent to experience and thereby modify future thought, behaviour and feeling. Neuronal activity can modify the behaviour of neural circuits by one of the three mechanisms : (a) by modifying the strength or efficacy of synaptic transmission at pre-existing synapses, (b) by eliciting the growth of new synaptic connections or the pruning away of existing ones, or (c) by modulating the excitability of individual neurons (Malenka, 2002). It is now reasonably well established that synapses are the primary sites of information storage, enabled by synaptic plasticity.

Synaptic plasticity is the cellular phenomenon by which synapses can undergo permanent changes in their properties consequent to specific patterns of activity. Since synaptic activity represents incoming information into the brain, the consequent permanent changes in synapses are thought to serve as the engram or record of the information. Hence mechanisms underlying synaptic plasticity events have attracted considerable attention as the molecular basis of learning and memory.

Synaptic plasticity was first proposed as a cellular mechanism for memory by Donald Hebb in 1949. According to Hebb's postulate, repeated communication between two neurons via

\footnotetext{
${ }^{*}$ Equal contribution

t Corresponding Author
} 
synaptic transmission can cause an enhancement in the efficacy of transmission between those neurons, brought about by biochemical changes at the synapses. Accordingly Hebbian conditioning needs both presynaptic and postsynaptic activity for its induction. This was followed by a search for instances where synaptic efficacy is altered. The discovery of Long term potentiation (LTP) by Bliss and Lomo in 1973 (Bliss \& Lomo, 1973) was the first demonstration of synaptic plasticity. LTP had all the characteristics necessary for a mechanism responsible for learning and memory and thus gained acceptance as a cellular correlate or cellular model system for learning and memory. Moreover, the cellular system with reduced complexity compared to the animal models was more amenable for interrogations at the molecular level. LTP thus became an essential component of a paradigm in which initial insights on molecular mechanisms are provided by experiments involving LTP which could then be validated in higher animal models.

In addition to the fundamental interest of how learning and memory are performed by brain, the study of synaptic plasticity is also attractive as it could lead to practical applications. The principles governing the workings of the molecular machineries involved in synaptic plasticity could be useful in the design of manmade memory devices. In the case of many CNS disorders, early aberrations at the molecular level are likely to involve synaptic plasticity mechanisms since the initial clinical symptoms very often involve cognitive impairments such as deficits in learning and memory. These mechanisms could be possible targets for early therapeutic intervention, provided they drive further molecular processes leading to the pathology of such diseases. Understanding of the mechanisms of synaptic plasticity would be of great therapeutic value in such instances.

A major challenge in understanding the molecular mechanisms of synaptic plasticity has been the diversity in the underlying mechanisms in different parts of the brain. The current article has reviewed the literature on molecular mechanisms that are involved in the induction and maintenance of different forms synaptic plasticity, mainly LTP and long term depression (LTD) and has attempted to simplify the scenario by extracting general features possessed by these mechanisms. Impairments in synaptic plasticity that could occur in disease conditions have also been touched upon.

\section{Synaptic plasticity}

The term Synaptic plasticity refers to the activity dependent changes in the efficacy of synaptic communication. Donald Hebb in 1949 developed a hypothesis about the mechanism of learning and memory at the neuronal level. Clinical observations enabled investigators to link human memory dysfunction to the hippocampus (Scoville \& Milner, 1957; Olds, 1972). These developments stimulated research in the field of synaptic plasticity in the mammalian brain (Blundon, 2008). Synaptic plasticity has been most extensively studied at the Schaffer-collateral pathway (Bliss, 2011) in the hippocampus, the seat of learning and memory, especially declarative memory. In 1973, Bliss and his associates reported that tetanic stimulation of the perforant pathway of presynaptic fibres resulted in high responses at postsynaptic sites on granule cells at the dentate gyrus region, to electric stimulation. The experiments were conducted in vivo with anaesthetized rabbits. They called the effect LTP because of the elevation of the postsynaptic potential, which could serve as a cellular substrate for information storage (Bliss \& Lomo, 1973). 
Several observations from a variety of species indicate that synaptic plasticity and memory are correlative. Behavioural and in vitro studies suggest that activity-induced synaptic modulations, such as LTP, play a role in information storage in the brain. This idea has been proposed as the "synaptic plasticity and memory (SPM) hypothesis" (Martin et al., 2000), and has been a major driving force behind the study of synaptic plasticity. Synaptic plasticity includes both short-term changes in the strength or efficacy of neurotransmission as well as longer-term changes in the structure of synapses (Kandel, 2001). Experimental models of changes in synaptic strength or effectiveness in response to repeated electrical stimulation are thought to mimic physiological plasticity at the neuronal level. The efficacy of synaptic transmission could increase as in LTP or it could decrease as in LTD as a result of plasticity. These modifications in synaptic strength, both positive and negative, distributed across millions of connections among neurons, are believed to form the physical and biochemical substrates for learning and memory.

Hippocampal LTP became a favourite model for the study of learning and memory due to the following reasons. First, there is compelling evidence from studies in rodents and higher primates, including humans, that the hippocampus is a critical component of the neural system involved in various forms of long-term memory. Second, several properties of LTP make it an attractive cellular mechanism for information storage. Like memories, LTP can be generated rapidly and is prolonged and strengthened with repetition. It is also input specific in that it is elicited at the synapses activated by afferent activity and not at adjacent synapses on the same postsynaptic cell (Malenka, 2002).

\section{Long term potentiation}

LTP is an activity-dependent, persistent enhancement of synaptic strength. LTP mainly occurs at glutamatergic synapses and is often measured in terms of the magnitude of excitatory post synaptic potential (EPSP) enhancement at a given time-point after induction. This measurement is influenced by the initial magnitude of potentiation and the decay rate of the potentiation and are independently regulated. Generally longer-lasting forms of plasticity are observed following repetitive or tetanic stimulation of synapses with prolonged (approximately 200-millisecond to 5-second) trains of stimuli applied at high frequencies (10 to $200 \mathrm{~Hz}$ ).

\subsection{Phases of LTP}

LTP is formed by a series of distinguishable mechanisms. LTP can be divided into two temporally distinct phases such as early and late phases. Early LTP (E-LTP) lasts for about 1$3 \mathrm{hrs}$ and requires modification of existing proteins and their trafficking at synapses but not de novo protein synthesis (Bliss \& Collingridge, 1993; Malenka \& Bear, 2004). This short lasting form of LTP can be induced by a weak, high frequency tetanus (single train of 100 pulses at $100 \mathrm{~Hz}$ ). Late LTP (L-LTP) requires the synthesis of RNA, new proteins and protein kinase activity especially cyclic adenosine 3', 5'-monophosphate (cAMP)-dependent protein kinase or protein kinase A (PKA) (Frey et al., 1993; Huang and Kandel, 1994; Nguyen et al., 1994), which lasts for up to 8-10 hrs in vitro and weeks in vivo. L-LTP can be induced by repeated strong high frequency stimulation such as multiple trains of 100 pulses at $100 \mathrm{~Hz}$ and is necessary for structural modification of synapses (Lu et al., 2007). 


\subsection{Types of LTP}

Even though plasticity events can be distinguished as either LTP or LTD, a huge variation in forms of LTP has also been observed. Several factors contribute to these different types of LTP. LTP varies with the type of molecular pathway involved in its induction as can be seen in the case of LTP in hippocampal CA1 region which is either N-methyl-D-aspartate receptor (NMDAR) dependent or independent. Different regions of brain show different forms of LTP. The age of the organism also contributes to the variation in LTP. LTP in neonatal ( $<9$ postnatal days) rodent hippocampal CA1 region is different from that in mature animals (Yasuda et al., 2003). Based on the pre and postsynaptic activity patterns required for induction, LTP can be classified as Hebbian, Non-Hebbian, anti-Hebbian and neo-Hebbian. Hebbian LTP requires both pre and post synaptic activity at the same time for its induction (Hebb, 1949). Non-Hebbian LTP requires activation of either pre or post synaptic compartment and does not need simultaneous depolarization of pre- and postsynaptic cells; an example of this occurs in the mossy fibre hippocampal pathway. AntiHebbian LTP can be formed by a conjunction of presynaptic depolarization and postsynaptic hyperpolarization (Lamsa et al., 2007). This can be induced in several classes of interneurons in strata oriens and pyramidale by high or low frequency stimulation patterns applied to axon collaterals of local pyramidal neurons, as long as the postsynaptic membrane potential is kept negative to the action potential threshold (Kullmann \& Lamsa, 2008). In addition to these three forms of LTP, neo-Hebbian LTP has been described recently which is related with the late phase of LTP induced by an NMDAR dependent process (Lisman et al., 2011). This form of LTP not only depends on the two factors of the Hebbian condition (glutamate release and postsynaptic depolarization), but also on a third factor, dopamine release. Dopamine will enhance the protein synthesis within the dendrites of hippocampal neurons (Smith, 2005).

Analyses of LTP decay rates and biochemical mechanisms have revealed three different forms of LTP (LTP-1, 2 and 3) in the hippocampus. LTP-1, induced by a single train of conditioning stimulation, is short lasting (2-3 $\mathrm{h}$ in vitro) and is dependent on post-translational modifications of existing synaptic proteins. LTP-2, induced by several repetitions of a conditioning train, is an intermediate form of LTP that depends on protein synthesis but not transcription of new mRNA. Finally, LTP-3, induced by multiple, spaced repetitions of conditioning stimulation, is very durable (perhaps even permanent in some cases, e.g. Abraham et al., 2002) and requires gene transcription and translation (Raymond, 2008).

\subsection{Properties of LTP}

Three key properties of LTP were elucidated in the 1970s and early 1980s. All of these can be explained using NMDA receptor dependent LTP mechanisms.

\subsubsection{Input specificity}

LTP can be generated only in those synapses which had undergone activation and not in adjacent synapses. But this is not valid for closely located synapses.

\subsubsection{Associativity}

One of the interesting properties of LTP mechanism is its associativity. If a weak non-LTP inducing stimulation in one afferent is paired with a strong LTP inducing stimulation in 
another afferent on the same cell, then the weakly stimulated afferent also exhibits LTP (Levy \& Steward, 1979). This property is called as associativity. This property makes LTP an attractive mechanism for associating two pieces of information being conveyed by different sets of afferents that synapse on the same postsynaptic cell (Malenka, 2003).

\subsubsection{Cooperativity}

LTP can also be generated by weaker stimulation of a crucial number of presynaptic fibres to achieve a threshold stimulation to activate a postsynaptic neuron to induce LTP. This property is called cooperativity because different presynaptic fibres are cooperatively eliciting LTP.

\subsubsection{Persistence}

In addition to the above mentioned three characteristics, persistence can also be included as a fourth characteristic. LTP is persistent, lasting from several minutes to many months as long as the memory persists.

\subsection{Molecular mechanisms of LTP}

The cellular and molecular mechanisms of LTP induction are comprised of many events such as covalent modification of pre-existing proteins, the activation of cellular programs for gene expression and increased protein synthesis. The regulatory events move from the synapse to the nucleus and then back to the synapse in the course of LTP induction.

LTP induction experiments have mostly been done in hippocampal excitatory synapses. The hippocampus is divided into three distinctive regions composed of three distinctive kinds of cells. The dentate gyrus (DG), which is composed of granule cells and the CA3 and CA1 regions, which are composed of pyramidal cells having different properties. These regions are connected by well defined pathways through which signals traverse the hippocampus. The perforant fibre pathway (pp) from the entorhinal cortex forms excitatory connections with the granule cells of the DG. The granule cells give rise to axons that form the mossy fibre pathway (mf), which connects with the pyramidal cells in area CA3 of the hippocampus. The pyramidal cells of the CA3 region project to the pyramidal cells in CA1 by means of the Schaffer collateral pathway (Fig. 1).

LTP is widely studied in the CA1 region of the hippocampus (Bliss and Collingridge, 1993; Reymann and Frey, 2007). The establishment of LTP in the CA1 region requires both presynaptic activity and large postsynaptic depolarization. The original stimulus protocol used by Bliss and Lomo in the anesthetized rabbit ranged from 10 to $100 \mathrm{~Hz}$ (Bliss \& Lomo, 1973). Since that time, a variety of LTP induction protocols from different research groups have emerged in the literature. Most involve trains of high-frequency stimulation (tetanization) that are delivered to presynaptic axons. The tetanization typically lasts several seconds and is delivered at frequencies of 25 to $400 \mathrm{~Hz}$.

The induction of LTP requires an influx of calcium into the postsynaptic neuron that can be either through NMDAR dependent or NMDAR-independent mechanisms. 


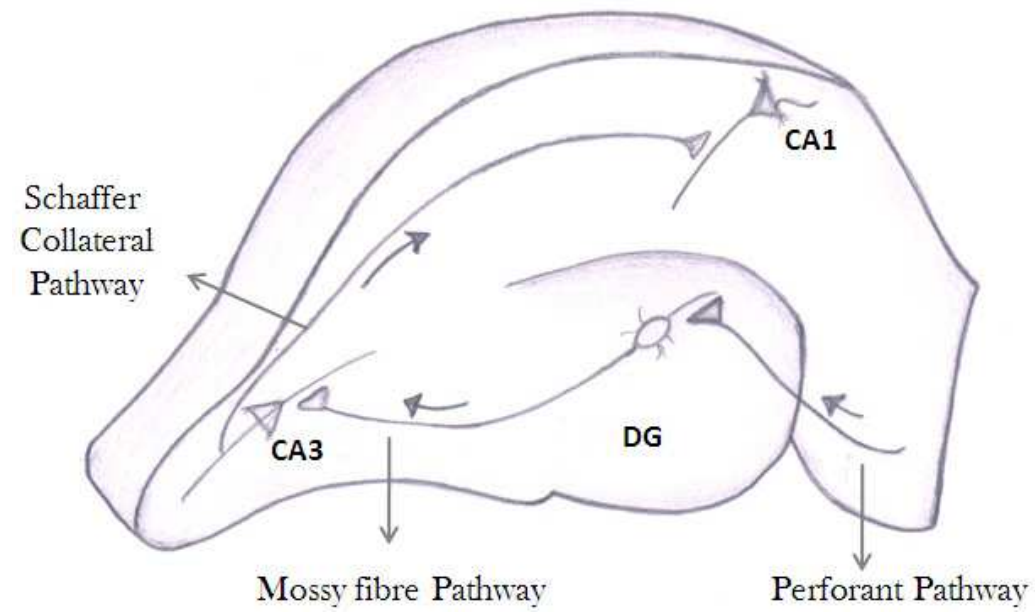

Fig. 1. Hippocampus

\subsubsection{NMDAR dependent mechanism (NMDAR-LTP)}

The best understood form of LTP is induced by the activation of the NMDAR complex. This subtype of glutamate receptor allows electrical events at the postsynaptic membrane to be transduced into chemical signals which, in turn, are thought to activate both pre and postsynaptic mechanisms to generate a persistent increase in synaptic strength.

Glutamate is a major excitatory neurotransmitter in the brain. During nerve impulse transmission, glutamate will be released into the synapse from the presynaptic terminal. Glutamate receptors present on the postsynaptic membrane are the initial triggers for the ensuing postsynaptic calcium signaling mechanism responsible for the induction of LTP. NMDA, a-amino-3-hydroxy-5-methyl-4-isoxazolepropionic acid (AMPA) and kainate receptors are the ionotropic-glutamate receptors present on the postsynaptic membrane. Among these NMDA and AMPA receptors play an important role in the induction of LTP. NMDARs are formed from hetero-tetrameric assemblies of GluN1 (previously NR1) subunits with GluN2A-D (NR2A-D) and Glu3A/B (NR3A/B). NMDARs require the binding of L-glutamate and the co-agonist glycine, as well as depolarization, to become activated and conduct $\mathrm{Na}^{+}, \mathrm{K}^{+}$and $\mathrm{Ca}^{2+}$ ions. AMPARs are composed of four subunits, GluA1-4 (previously GluR1-4). The Q/R edited GluA2 subunit is critical for the biophysical properties of AMPARs producing low conductance, non-rectifying, $\mathrm{Ca}^{2+}$-impermeable AMPARs. Postnatally the great majority of AMPARs contain edited GluA2 in excitatory synapses.

Glutamate binding to the AMPA receptor leads to a sodium influx into the postsynaptic compartment. This leads to depolarization causing release of $\mathrm{Mg}^{2+}$ block present on the NMDA receptor. The binding of glutamate and the removal of $\mathrm{Mg}^{2+}$ block causes NMDA receptor to open and conduct $\mathrm{Ca}^{2+}$ and $\mathrm{Na}^{+}$into the cell. The influx of $\mathrm{Ca}^{2+}$ is essential for LTP induction. With repeated activation of the neuron, sufficient calcium will enter into the postsynaptic compartment and triggers the molecular events needed for the induction of 
LTP. This calcium influx activates several important signaling pathways involving different protein kinases and phosphatases. One of the kinases activated by the influx of calcium through NMDARs is $\mathrm{Ca}^{2+}$ /calmodulin dependent protein kinase II (CaMKII), which is known as the memory molecule. CaMKII is a Ser/Thr protein kinase, abundant in glutamatergic postsynaptic terminal. The activation of CaMKII by $\mathrm{Ca}^{2+} / \mathrm{CaM}$ complex leads to the formation of autophosphorylated enzyme at $\mathrm{Thr}{ }^{286}$ position, which will make it calcium independent. Thus the $\mathrm{Thr}^{286}$ autophosphorylated form of the enzyme will maintain its activity even though $\mathrm{Ca}^{2+} / \mathrm{CaM}$ complex is removed from its regulatory domain. The autophosphorylation can enhance binding affinity of the enzyme for $\mathrm{Ca}^{2+} / \mathrm{CaM}$ by a 1000 fold. Studies have shown that $\mathrm{Thr}^{286}$ autophosphorylated enzyme is required for the induction of LTP. Upon activation, CaMKII can rapidly translocate to the postsynaptic density (PSD), where postsynaptic receptors such as AMPAR and NMDAR are concentrated. The translocated CaMKII can bind to different subunits of NMDAR such as GluN1, GluN2A and GluN2B, which are the ideal postsynaptic adapters. Of these, GluN2B-CaMKII interaction is well characterized and is essential for the induction and maintenance of LTP (Barria \& Malinow, 2005; Lisman et al., 2011). The AMPAR is one of the substrates for CaMKII (as well as for PKC) in the PSD where CaMKII can phosphorylate GluA1 subunit of AMPAR at Ser ${ }^{831}$. This phosphorylation of GluA1 by CaMKII (Barria et al., 1997b) leads to an increased conductance of homomeric GluA1 channels (Derkach et al., 1999) and is believed to be one of the major contributors to the enhanced efficacy of glutamatergic synapses in CA1 area of hippocampus during LTP (Fig. 2).

LTP can occur either in AMPAR containing synapses or in synapses lacking AMPAR. When a glutamatergic synapse is formed, only NMDAR will be present in the postsynaptic membrane. Such synapses lacking AMPA receptors are called silent synapses, where AMPAR gets inserted in the postsynaptic membrane during the activation of nearby synapses. As a consequence of NMDAR activation and the resulting $\mathrm{Ca}^{2+}$ influx into the post synaptic dendrite, new AMPARs get inserted into the post synaptic membrane. This 'AMPAfication' of the synapse makes the transmission stronger (Bear, 2001). Thus enhanced AMPAR activity either by increase in AMPAR abundance in the synapse or by increase in the conductivity of AMPARs is the key postsynaptic mechanism leading to increase in EPSP response seen in LTP. Studies have shown that activated forms of a-CaMKII can enhance the synaptic trafficking of AMPARs. PKA can also participate in AMPAfication by phosphorylating GluA1 at Ser ${ }^{845}$ which enhances AMPAR exocytosis (Oh, 2005). AMPAR recruitment mediated by PKA is shown in Fig. 3. Activation of PKA also boosts the activity of CaMKII indirectly by decreasing the competing protein phosphatase activity especially protein phosphatase 1(PP1). PKA inhibits PP1 by activating the inhibitor of PP1 called inhibitor-1(Bryne, 2009).

Several other protein kinases, including protein kinase $C$ (PKC), PKA, the tyrosine kinase Src, and mitogen-activated protein kinase (MAPK), have also been suggested to contribute to LTP (Teyler et al., 1987). The evidence in support of critical roles for these kinases is, however, considerably weaker than that for CaMKII. PKC has been suggested to play a role analogous to that of CaMKII, because PKC inhibitors have been reported to block LTP and increasing postsynaptic PKC activity can enhance synaptic transmission (Hu et al., 1987). 


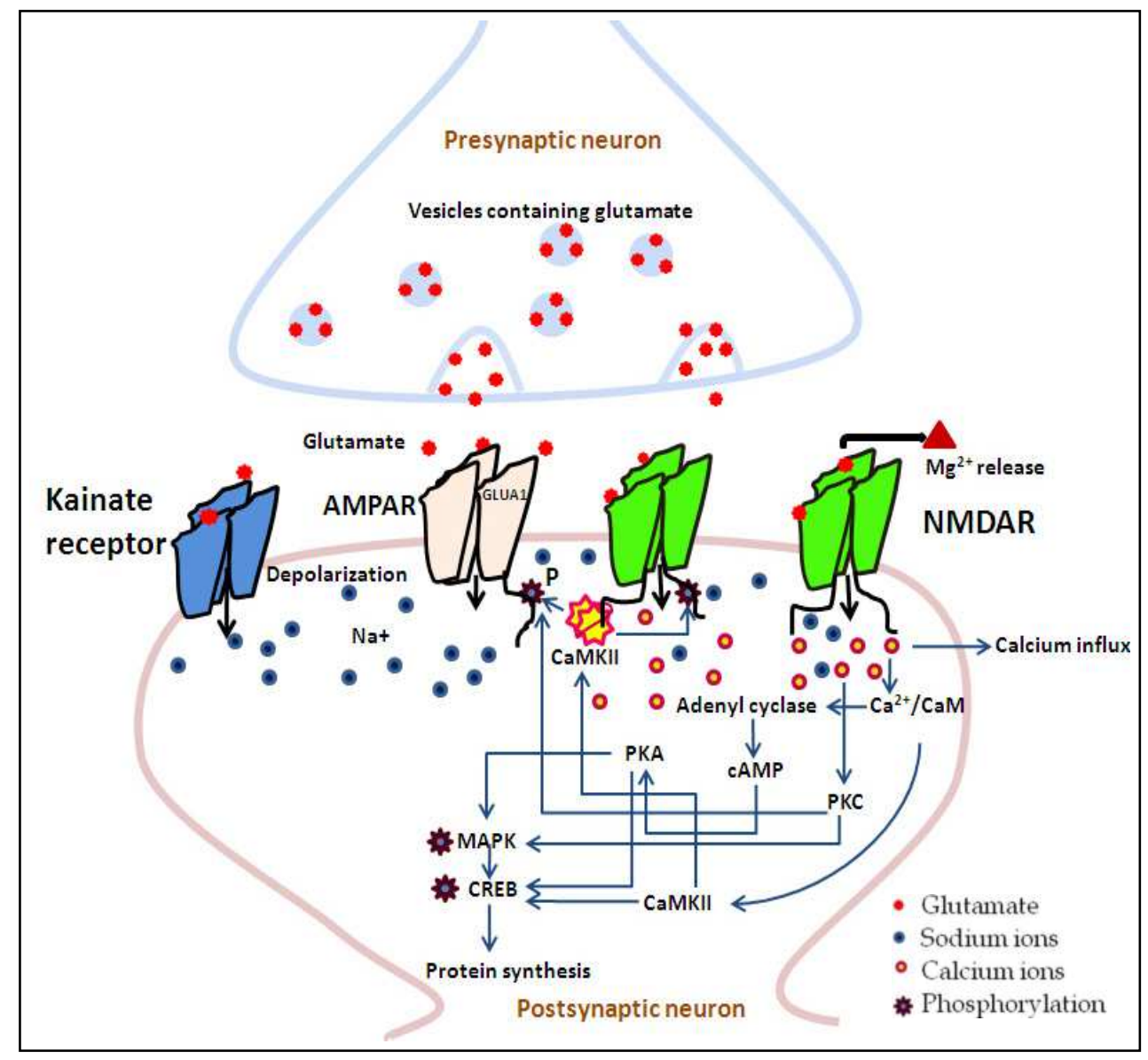

Fig. 2. Molecular mechanisms of NMDAR Dependent LTP.

The calcium influx through NMDAR also activates adenyl cyclase, which generates cAMP in the postsynaptic compartment. This second messenger generated thus triggers a series of downstream signalling mechanisms, which function more in LTP maintenance. The local increase in cAMP levels leads to the activation of PKA by causing the catalytic subunits of this enzyme to dissociate from the regulatory subunits.

The activated PKA can regulate gene expression. PKA can modify transcription by phosphorylating several different transcription factors, one of which is the cAMP response element binding protein (CREB). CREB is a nuclear protein that modulates transcription of genes containing cAMP response elements (CRE) in their promoters (Kandel, 2001). The catalytic subunits of PKA can translocate to nucleus and phosphorylate serine-133 on CREB. 


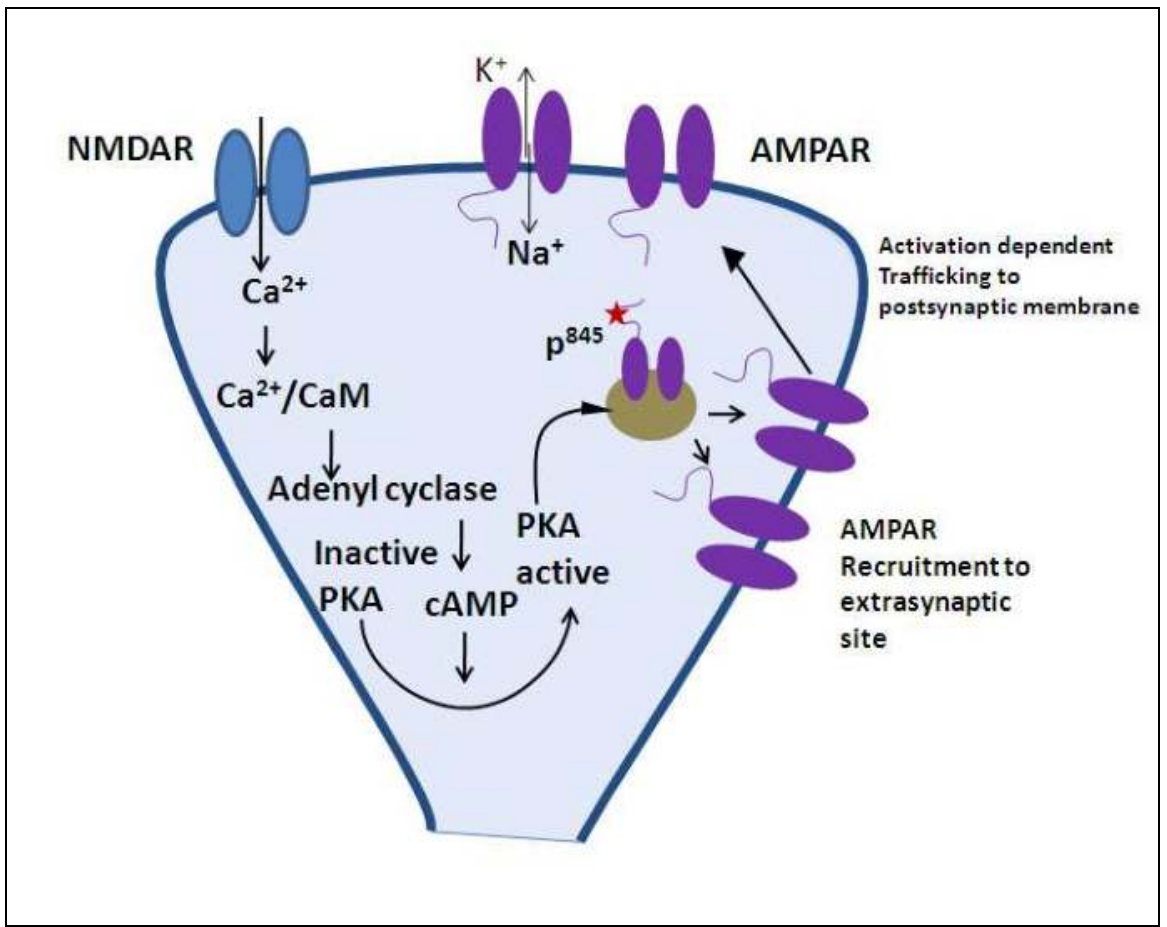

Fig. 3. AMPAR exocytosis regulation by PKA. $\mathrm{Ca}^{2+}$ signaling can activate PKA via adenyl cyclase-cAMP pathway. PKA can phosphorylate GluA1 subunit of AMPAR at Ser ${ }^{845}$ and this leads to the recruitment of AMPARs into extrasynaptic site. This extrasynaptic pool of AMPARs can then diffuse to PSD during NMDAR activation.

This phosphorylation can initiate transcription of CRE-associated genes. One protein that is regulated by the CREB family of transcription factors is brain-derived neurotrophic factor (BDNF), a key regulator in the conversion of E-LTP to L-LTP. BDNF can bind to a specific receptor tyrosine kinase, TrkB. This binding results in dimerization and autophosphorylation of the Trk receptors, leading to activation of the tyrosine kinases. Activated receptors in general are capable of triggering a number of signal transduction cascades including the MAPK pathway, the phosphatidylinositol 3-kinase (PI3K) pathway, and the phospholipase C$\gamma($ PLC- $\gamma$ ) pathway. The signals thus generated also can pass on to the nucleus to cause further activation of transcription factors and alterations in gene expression ( $\mathrm{Lu}, 2003)$.

PKA can also recruit MAPK to the nucleus where it can phosphorylate other kinases and transcription factors (eg: CREB) to activate gene transcription. Extra cellular signal regulated protein kinase (ERK), is a member of the mitogen-activated family of protein kinases, which play a crucial role in L-LTP. ERK activity is required to initiate the local translation of messenger RNAs (mRNAs) that are present at spines into functional proteins. Another function of ERK is its rapid translocation into the nucleus of the neuron where it phosphorylates several regulatory transcription factors. This leads to the transcription of several mRNAs that are transported along dendrites toward the spines and their synapses. 
The tyrosine kinases Src and Fyn indirectly affect LTP by modulating NMDAR function. These Src family of tyrosine kinases can alter NMDAR function by phosphorylating GluN2A and 2B subunits, thereby relieving a basal zinc inhibition of the NMDAR. Phosphorylation of GluN2A or 2B thus potentiates the current through NMDAR complex. The increase in calcium concentration thus produced can contribute to the process of LTP.

Recent studies indicate that another subclass of glutamate receptors, the metabotropic glutamate receptors (mGluRs) are also involved in LTP induction (Bashir, 1993). In addition to activating ion channel-linked receptors, glutamate activates $G$ protein-coupled metabotropic receptors which exist in eight different types labeled $\mathrm{mGluR}_{1}$ to $\mathrm{mGluR}_{8}$ which are classified into groups I, II, and III. Receptor types are grouped based on receptor structure and physiological activity. mGluR subtypes 1 and 5 (group I mGluRs) are positively coupled to phospholipase C (PLC), and trigger elevations in intracellular inositol triphosphate (IP3) and diacylglycerol (DAG), followed by mobilization of $\mathrm{Ca}^{2+}$ and activation of PKC (Benquet, 2002). Group I mGluRs are known to modulate the function of NMDAR by binding to PDZ proteins near to NMDAR (Yu, 1997). The activation of mGluRs, especially $\mathrm{mGluR}_{5}$ is involved in the induction of large amplitude or long-lasting late phase LTP of AMPAR-mediated transmission induced by strong or repeated stimulation protocols (Anwyl, 2009).

\subsubsection{Maintenance of LTP}

While LTP induction involves enhancement of synaptic efficacy largely by the biochemical events of E-LTP, the long term maintenance of the potentiated state demands for stable and self-sustaining biochemical mechanisms. In the dynamic milieu of the cell where most changes are reversible, stable alterations can be brought about by changes in the size of molecular pools that are dynamically maintained or by establishment of cyclic pathways which can maintain themselves. Increased exocytosis of AMPARs to the synaptic membrane could increase the size of the AMPAR pool in the synapse thereby increasing the response of the synapse. Phosphorylation of AMPARs leads to an increase in the pool of AMPARs with increased conductivity. However sustained maintenance of the larger pools requires adjustments in the kinetics of the pathways that influence these pools. One of the molecules that had been viewed as a candidate for maintenance of the stable state is CaMKII. Theoretical analysis indicates that the pool of CaMKII molecules in the special chemical environment of the PSD acts as a bistable switch. According to this model, the activity level of kinases and phosphatases determine which kind of synaptic plasticity, LTP or LTD is induced. A switch of this kind turns on, when a threshold number of $\mathrm{Thr}^{286}$ sites on the kinase are phosphorylated. Thr286-autophosphorylation converts CaMKII to an autonomously active 'on' state. The 'on' state of the switch can last for very long periods, because the kinase acts faster than the PSD phosphatase on Thr ${ }^{286}$ sites (Lisman, 2002). In the early phase of LTP, phospho-CaMKII generated will be more due to the fast activity of the kinase. Activated form of CaMKII can bind to the GluN2B subunit of the NMDAR as described earlier. This binding leads to saturation of CaMKII at very low concentration of ATP and thereby stabilizes the activity of the kinase against variations in the concentrations of ATP at synapses (Pradeep et al., 2009). This binding also leads to reduction in the rates of the phosphorylation and dephosphorylation reactions, resulting in a reduction in the amount of ATP consumed while running the simultaneous kinase and phosphatase reactions. Thereby this biochemical mechanism permits the functioning of the kinase- 
phosphatase switch in an energy efficient manner (Cheriyan et al., 2011). Activated CaMKII can function in enhancing AMPAR currents and its recruitment. This will contribute to the maintenance of enhanced AMPAR mediated postsynaptic response.

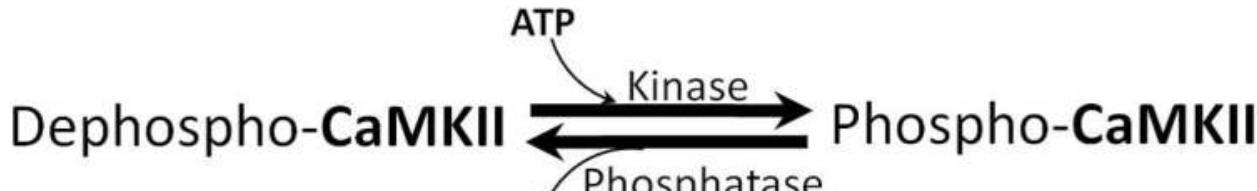 $\mathrm{H}_{2} \mathrm{O}$}

Fig. 4. CaMKII-phosphatase bistable switch model. Continuous interconversion between CaMKII and phospho-CaMKII is catalysed by the kinase activity of $\mathrm{Thr}^{286}$ autophosphorylated CaMKII and the phosphatase activity of PP1.

Activated PKA can also contribute to the maintenance of LTP by involving in a selfsustaining mechanism, in addition to its role in promoting AMPAR exocytosis. As described earlier, activated PKA can alter gene expression via cAMP-PKA-CREB pathway. One gene activated by CREB encodes a ubiquitin hydrolase, a component of a specific ubiquitin protease that leads to the regulated proteolysis of the regulatory subunit of PKA. This results in persistent activity of PKA, leading to persistent phosphorylation of PKA substrates such as CREB, MAPK, etc., thereby completing a self-sustaining cycle that can be stably maintained.

\subsubsection{Synaptic tagging hypothesis}

L-LTP requires de novo protein synthesis. The long lasting activity changes require nuclear transcription followed by delivery of newly synthesized proteins to the synapse to yield synaptic remodeling. Newly synthesized proteins delivered by non-directed transport from the cell body must be captured locally at the activated synapse in order to function in an input-specific manner (Doyle, 2011). For this, the activated synapse requires a local signal that allows it to capture proteins or mRNAs for protein-synthesis-dependent LTP or LTD. This process has been termed synaptic tagging. Based on this proposal, synaptic activity generates a tag, which "captures" the plasticity-related proteins (PRPs) derived outside of synapses (Lu et al., 2011). These findings indicate a tight and extensive dialogue between the synapse and the nucleus in both directions.

\subsubsection{3 mRNA transport into the dendrites}

mRNA localization to the synapses depends on synaptic activity and the mechanism behind this transport is largely a mystery. This transport mechanism is highly complex and involves multiple mRNA binding proteins. This process can be divided into different stages, (1) the presence of cis-acting localization elements (LEs) or zipcodes generally located in the $3^{\prime}$-untranslated region ( $3^{\prime}$-UTR) of localized transcripts, (2) the recognition of these signals by trans-acting RNA-binding proteins (RBPs), (3) the assembly of RBPs and their cargo 
RNAs into transport ribonucleo-protein particles (RNPs) as a functional complex, (4) the translocation of transport RNPs along the microtubule (MT) cytoskeleton to their final destination at synapses in a translationally repressed state, (5) the anchoring of these particles at or underneath activated synapses in a translationally repressed state and finally (6) the activation of translation of the localized mRNAs (Doyle, 2011).

One of the specific immediately expressed candidate gene is activity-regulated cytoskeletonassociated protein (Arc). Newly synthesized Arc mRNA is targeted rapidly to synapses that have recently undergone specific forms of synaptic activity where it is locally translated. Targeting of Arc mRNA depends on NMDAR activity. An increase in Arc expression promotes stable expansion of the F-actin network in dendritic spines, which is believed to underlie morphological enlargement of the synapse and stable LTP (Bramham, 2010).

\subsubsection{Spine enlargement}

Most excitatory synapses in the brain terminate on dendritic spines. Spines are specialized perturbations on dendrites that contain PSD. The PSD includes receptors, channels and signaling molecules that couple synaptic activity with postsynaptic biochemistry. Spines provide a closed compartment that allows rapid changes in the concentrations of signaling molecules, such as calcium, and hereby make efficient responses to inputs possible. Longterm changes in spine morphology could contribute to the modulation of synaptic transmission that occurs in LTP. Shortening or widening the neck of a spine affects calcium influx into the dendrite. Spine enlargement depends on the structure of cytoskeletal filaments. Actin filaments of microfilaments are in close association with PSD. Reorganization of actin filament contributes to the spine enlargement process in LTP. The AMPA class of glutamate receptors has been found to have a stabilizing effect on spine morphology. Rho GTPases and their downstream effectors have an important role in regulating the cytoskeleton, and consequently in regulating spine and dendritic morphology, in response to extracellular stimulation. AMPAR activation by spontaneous glutamate release at synapses is sufficient to maintain dendritic spines (Lamprecht \& LeDoux, 2004).

\subsubsection{Presynaptic mechanisms}

Activation of both pre and postsynaptic sites are necessary for the generation of LTP on the basis of Hebbian theory. Neurotransmitter release is one of the presynaptic mechanisms eliciting the induction of LTP. An increase in neuro-transmitter release can be observed together with the postsynaptic mechanisms. This is due to the activation of presynaptic terminals by some factors released by the postsynaptic compartment or cell (Williams et al., 1989). A prominent candidate for such a messenger is arachidonic acid or one of its metabolites, because these compounds can readily cross cell membranes. This can be generated by the degradation of phospholipids by the enzyme phospholipase $\mathrm{A}_{2}$, a calcium dependent enzyme (Bliss, 1990). Nitric oxide (NO) is another retrograde messenger produced by $\mathrm{Ca}^{2+} / \mathrm{CaM}$ activated nitric oxide synthase (NOS), which can activate the synthesis of cyclic GMP presynaptic terminal by activating two NO-sensitive guanylyl cyclases (NO-GCs) (NO-GC1 and NO-GC2) leading to increased neurotransmitter release. The physiological consequences of increase in NO/cGMP and the associated cellular mechanisms involved are not well understood. 


\subsubsection{NMDAR-independent mechanisms}

Although a vast majority of studies of NMDAR dependent LTP have been conducted, there are also a few mechanisms that are independent of NMDAR that have been studied. Following section will briefly describe molecular mechanisms of NMDAR independent forms of LTP.

\subsubsection{1 $200 \mathrm{~Hz}$ LTP}

NMDAR-independent forms of LTP also can be induced at the Schaffer collateral pathway in CA1. This allows for a comparison of two different types of LTP at the same synapse. NMDAR-independent LTP in CA1 can be elicited by use of four and a half seconds, $200 \mathrm{~Hz}$ stimuli separated by five seconds. LTP induced by this stimulation protocol is insensitive to NMDAR selective antagonist such as APV. $200 \mathrm{~Hz}$ LTP was shown to be blocked by nifedipine (Grover and Teyler, 1990), a voltage gated calcium channel (VGCC) blocker. This observation led to the conclusion that $200 \mathrm{~Hz}$-LTP stimulation elicits sufficiently large and prolonged membrane depolarization, resulting in the opening of voltage dependent calcium channels, to trigger elevation of postsynaptic calcium sufficient to trigger LTP. It is also reported that L-type $\mathrm{Ca}^{2+}$ channel-dependent synaptic plasticity significantly contributes to spatial learning in the behaving mouse (Moosmang et al., 2005).

\subsubsection{Tetra-Ethyl-Ammonium LTP}

NMDAR-independent LTP at the Schaffer collateral pathway in CA1 can also be induced by the bath application of the $\mathrm{K}^{+}$channel blocker tetraethylammonium (TEA) (TEA-LTP) (Aniksztejn and Ben-Ari, 1991) and is referred to as LTPk. This nonspecific potassium channel blocker can cause membrane excitability. Like $200 \mathrm{~Hz}-\mathrm{LTP}$, TEA-LTP is insensitive to NMDAR antagonists, and is blocked by blockade of voltage sensitive calcium channels. The induction of LTPk is dependent on synaptic activity, as its induction is blocked by AMPAR antagonists. Similar to $200 \mathrm{~Hz}$ LTP, the current model for TEA-LTP is that synaptic depolarization via glutamate receptor activation, augmented by the hyperexcitable membrane due to $\mathrm{K}^{+}$channel blockade, leads to a relatively large and prolonged membrane depolarization. This leads to the triggering of LTP through postsynaptic calcium influx via the VGCCs.

\subsubsection{Mossy fiber LTP in CA3}

A good model system for studying NMDAR-independent LTP is the mossy fiber inputs into CA3 pyramidal neurons. The mossy fiber synapses are unique, large synapses with unusual presynaptic specializations. The mechanism will be described in later section (3.5.).

\subsubsection{Chemical LTP (Chem-LTP)}

Early protocols for the induction of LTP in cultures of dissociated hippocampal neurons comprised repetitive high frequency presynaptic stimulation (HFS-LTP) as mentioned above. In some cases this was coupled with postsynaptic depolarization and in others cultures were preincubated with blockers of different channels. High frequency stimulation activates only a small fraction of synapses, making it difficult to detect molecular and cellular changes associated with LTP. Most biochemical analysis and imaging studies require a high proportion of synapses to be potentiated. Therefore, a range of strategies 
were applied to chemically induce LTP (Chem-LTP). Chem-LTP is an alternative to high frequency stimulation and has the advantage that it can activate all the cells in the culture. One example of Chem-LTP is mentioned below.

\subsubsection{Forskolin/rolipram-induced LTP}

Forskolin/rolipram-induced LTP was predominantly used in slice cultures; it can also be applied for dissociated hippocampal neuronal cultures. This form of chemically induced, highly sensitive plasticity state is based on the increase of intracellular cAMP levels by the application of the adenylyl cyclase activator forskolin $(50 \mu \mathrm{M})$ and the phosphodiesterase inhibitor rolipram $(0.1 \mu \mathrm{M})$ in $\mathrm{Mg}^{2+}$ and 2-Cl-adenosine free artificial cerebrospinal fluid for 16 min (Otmakhov, 2004). This induction procedure is bypassing the need for synaptic activation, and by raising cAMP concentration directly activates PKA and signaling pathways that underlie synaptic plasticity. However, froskolin/rolipram-LTP still require NMDAR activation and involve the recruitment of CaMKII to dendritic spines (Molnar, 2011).

\subsection{LTP in other regions of CNS}

Although LTP was first described at the perforant path synapses on the neurons of the DG, subsequently most of the work on the mechanism of LTP is performed on the Schaffer collateral synapses on the CA1 pyramidal neurons.

In the CA1 region, NMDAR-mediated and NMDAR-independent LTP have been described and they are expressed mainly as postsynaptic mechanisms. Presynaptic LTP was also discovered in hippocampus and cerebellum. In hippocampus, presynaptic LTP can be observed in mossy fiber pathway. There is no need for calcium influx in the postsynaptic compartment for eliciting this form of LTP and this is NMDAR-independent. In the induction of presynaptic LTP, presynaptic calcium release is essential. R-type calcium channels are voltage dependent calcium channels that can mediate presynaptic calcium release. This calcium influx can activate several signaling pathways needed for the induction of mossy fiber LTP (MF-LTP). Both pharmacological and genetic analyses indicate that a rise in presynaptic cAMP is a crucial component. The cAMP level is enhanced by the activation of $\mathrm{Ca}^{2+} / \mathrm{CaM}$ activated adenyl cyclase 1 (AC1) and leads to the activation of PKA. This PKA activation regulates key molecules needed for the enhanced neurotransmitter release (Nicoll, 2005).

\subsubsection{Cerebellar LTP}

In cerebellum, parallel fibres (PF) of cerebellar granule cells form synapse with Purkinje cells (PC) of Purkinje cell layer (Fig. 5). When the PF is stimulated at $4-8 \mathrm{~Hz}$ for $15 \mathrm{~s}$, a presynaptic form of LTP is induced at PF. This shows a similar molecular mechanism as that of the mossy fiber pathway in the hippocampus. A postsynaptically expressed form of LTP was more recently described and is observed as a reversal of PF-LTD. PF-LTP can be induced by repetitive $\mathrm{PF}$ stimulation ( $1 \mathrm{~Hz}$ for 5 minutes) without concomitant $\mathrm{CF}$ activation and requires a lower calcium transient for its induction than PF-LTD (Vogt \& Canepari, 2010). PF-LTP generally depends on the activation of phosphatases such as PP1, PP2A, and PP2B and is independent of activity of kinases such as CaMKII and PKC (Jorntell \& Hansel, 2006). In cerebellar PCs, GluR1 expression is weak, and the majority of AMPA receptors consist of 
GluR2-GluR3 heteromeric complexes. An activity dependent synaptic delivery of GluR2 has been shown during the induction of LTP in PF-PC synapses. This activity driven process involves NO-mediated binding of N-ethylmaleimide sensitive factor (NSF) to GluR2. In PF LTP, GluR2 synaptic delivery is also facilitated by dephosphorylation of GluR2 at Ser ${ }^{880}$.

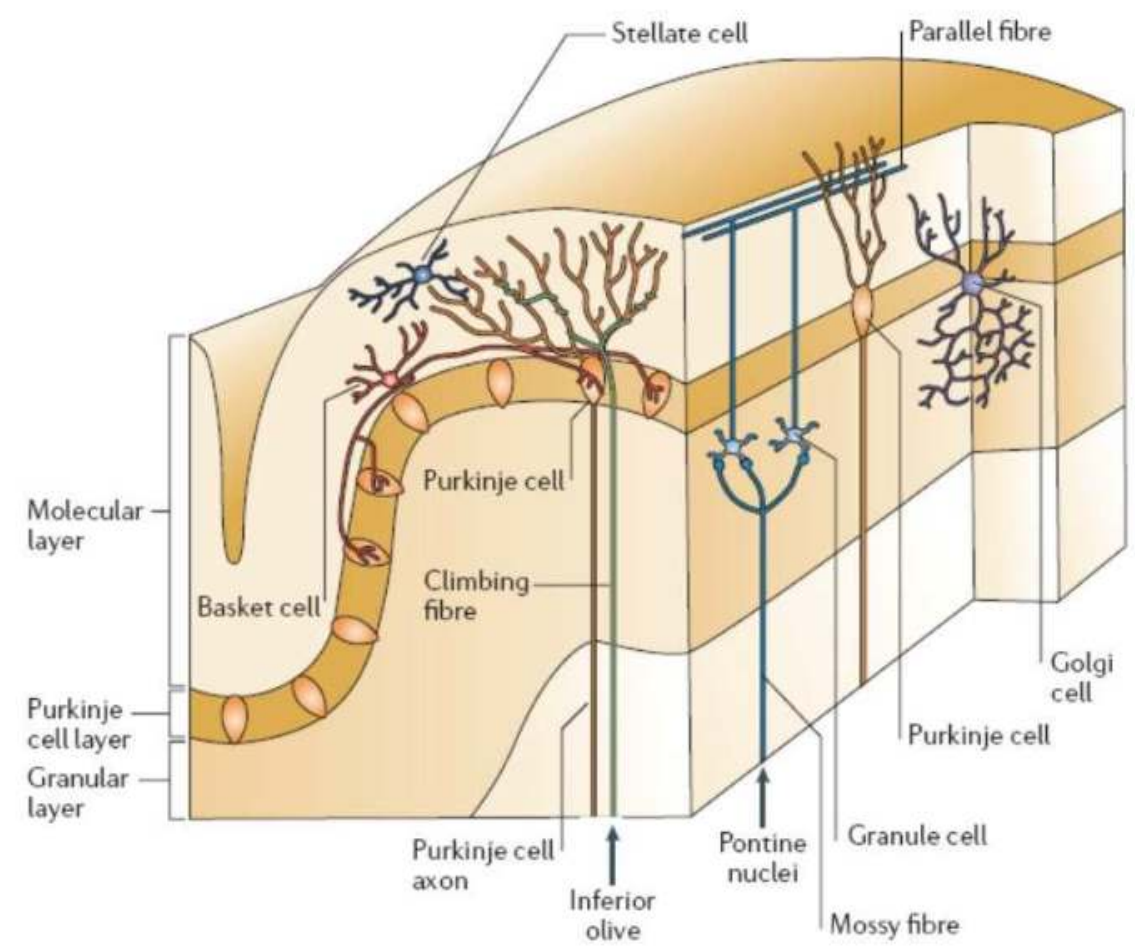

Fig. 5. Cellular anatomy of the cerebellum. Adapted from Ramnani, 2006

\subsubsection{LTP in spinal cord}

Spinal LTP has been demonstrated in different areas of the spinal cord. The ventral and the superficial dorsal horn, Wide Dynamic Range (WDR) neurons and superficial neurons in the spinal cord that project to the parabrachial area in the brain stem are some of the sites where LTP has been demonstrated. It has been suggested that the generation of LTP in spinal cord may be one mechanism, whereby acute pain may be transformed into a chronic pain state. LTP in superficial spinal dorsal horn involves simultaneous activation of multiple receptors like the NMDAR, the Neurokinin 1 (NK-1) receptor for substance P and mGluRs. This LTP is likely to occur in both the sensory and the affective pain pathways. LTP in deep spinal WDR neurons have a pivotal role in transmission of painful inputs. As with LTP in the superficial spinal cord, activation of the ionotrophic glutamate receptors (AMPA and NMDA subtypes) and the NK1 receptor seems crucial for the induction of LTP in deep WDR neurons (Rygh et al, 2005). 


\section{Long term depression}

LTD is an activity dependent reduction in the efficacy of neuronal synapses. It can generally last for hours or longer. It brings about a long lasting decrease in synaptic strength. LTD can be defined as a long lasting decrease in the synaptic response of neurons to stimulation of their afferents following a long patterned stimulus (Collingrigde et al., 2010). LTD is generally considered as a reversal of LTP as it is understood that if synapses continue to increase in strength, eventually they would reach some level of maximum efficacy which might cause saturation and then they may be unable to encode new information. This would result in neurons coming to a stage of complete inactivity or over activity. LTD is also considered to be the initial step in synaptic elimination (Bastrikova et al., 2008; Beckner et al., 2008) as it is known that those synapses which lose their efficacy are eliminated.

\subsection{Types of LTD}

LTD can be either homosynaptic or heterosynaptic. Homosynaptic LTD is induced by a conditioning input. It is input specific. It is restricted to the individual synapse which is activated by a low frequency stimulus (LFS) i.e., it happens in the same synapse that receives the induction. It is associative and it correlates with postsynaptic activation of the neuron by an active presynaptic neuron. Homosynaptic LTD is in turn of two types. LTD which follows an LTP is often known as depotentiation. If LTD is observed from base line conditions, with low frequency stimulus, then it is de novo LTD. Heterosynaptic LTD refers to depression at synapses neighboring the activated ones but are not directly activated themselves (Abraham et al., 2007). Heterosynaptic LTD occurs at synapses that are not potentiated. It occurs consequent to a non-conditioning input in association with either LTP or LTD. LTD relies on both pre and postsynaptic expression mechanisms although the maintenance mechanism is not fully understood (Bliss and Cooke, 2011).

\subsection{LTD in Hippocampus}

Unlike LTP, LTD in hippocampus occurs when the postsynaptic cells are weakly depolarized, whereas LTP induction involves strong postsynaptic depolarization. The hippocampal LTD is governed by BCM (Bienenstock Cooper Munro) theory (Bienenstock et al., 1982). It says that the synapses that are active when the postsynaptic cells are weakly polarized undergo LTD. If APs preceed EPSPs, LTD results; i.e., unpaired stimulation causes lower calcium signals and therefore LTD.

In the CA1 region LTD is homosynaptic, and depends on NMDARs and on protein synthesis but in the DG, it is independent of NMDARs and protein synthesis and is found both as heterosynaptic and homosynaptic forms (Kemp and Vaughan, 2007).

The best understood type of LTD is induced in hippocampal area CA1 by LFS via an NMDAR dependent rise in postsynaptic intracellular calcium and the activation of a protein phosphatase cascade which will be discussed hereforth. A brief application of NMDA can also lead to depression, i.e., a form of chem-LTD. LTD is triggered by postsynaptic calcium entry, like LTP, after activation by presynaptic stimulus. The main receptors involved are AMPAR and NMDAR. If the postsynaptic depolarization by AMPAR is weak, it cannot activate NMDARs completely. The partial removal of $\mathrm{Mg}^{2+}$ block results in reduced $\mathrm{Ca}^{2+}$ entry. 
Therefore instead of kinases, phosphatases get activated as they require comparatively lower $\mathrm{Ca}^{2+}$ concentrations for activation. The protein phosphatase activated is PP2B or calcineurin. PP2B can in turn activate PP1. PP2B dephosphorylates and inactivates Inhibitor-1. This relieves the inhibition of PP1 by Inhibitor-1 thereby activating it (Mulkey et al., 1993).

In hippocampus, plasticity is mediated by conductance changes of AMPARs which are in turn regulated by phosphorylation. The majority of AMPARs at hippocampal synapses are GluR1/GluR2 and GluR2/GluR3 heteromers. The trafficking of GluR1 plays a dominant role in plasticity. Activated PP1 brings about dephosphorylation of GluR1 at Ser ${ }^{845}$ (Fig. 6) and promotes AMPAR internalization (Lee et al., 2000). Inhibition of PP2B blocks GluR1 internalization and thereby LTD, suggesting the importance of phosphatase activity in LTD (Beattie et al., 2000). Targeting PP1 precisely to synapses upon NMDAR activation is crucial for LTD expression and is facilitated by PP1 binding proteins like spinophilin, neurabin, etc. (Morshita et al., 2001). In hippocampus, AMPARs are stabilized on the membrane by NSF and clathrin adaptor protein AP2, which bind to the NSF binding site on GluR2. During NMDARLTD, AP2 replaces NSF and this initiates AMPAR endocytosis. Clathrin mediated endocytosis of AMPARs is triggered by a neuronal calcium sensor known as hippocalcin. Upon activation, hippocalcin translocates to the plasma membrane, where it forms a complex with AP2 and GluR2 and initiates clathrin mediated AMPAR endocytosis. Protein interacting with C-kinase 1 (PICK1) is another protein that binds directly to GluR2 and it can also bind to PKC. PICK1 competes with AMPAR binding protein (ABP) and glutamate receptor interacting protein (GRIP) for binding to C-terminal of GluR2 and promotes internalization. PICK1 also helps in modifying neuronal architecture by interacting with F-actin. PP2B interacts with A-kinase anchor protein-150 (AKAP-150) which in turn interacts with PSD-95. PSD-95 further interacts with NMDAR thereby positioning PP2B near NMDAR (Bhattacharya et al., 2009). This helps in the activation of PP2B by $\mathrm{Ca}^{2+}$ influx through NMDARs. Activated PP2B can mediate the NMDAR-induced endocytosis of AMPARs that underlies one major form of LTD. Disruption of the interaction between PSD-95 and AKAP-150 strongly inhibited NMDAR-dependent endocytosis of AMPARs (Bhattacharya et al., 2009). Phosphorylation of Ser 295 of PSD-95 occurs in vivo, and it enhances the ability of PSD-95 to accumulate in the PSD, to recruit surface AMPA receptors, and to strengthen synaptic transmission. During LTD, PSD-95 is dephosphorylated at Ser 295 facilitating its removal from PSD. This mechanism also plays a role in the NMDAR-dependent endocytosis of AMPAR (Kim et al., 2007).

Although a major form of LTD is mediated by NMDARs, the ultimate direction of change in synaptic efficacy is brought about by changes in AMPAR function (Collingridge et al., 2010). Calcium influx through the NMDAR is central to the induction of both LTP and LTD because intracellular application of calcium chelators, such as BAPTA or EGTA, prevents induction of plasticity. Since induction of LTP and LTD are controlled by the postsynaptic NMDAR, any presynaptic component of expression requires a retrograde messenger that can signal to the presynaptic terminal that coincidence has occurred. Two candidates are nitric oxide (NO) and endocannabinoids (eCB) (Bliss \& Cook, 2011). Narachidonylethanolamine (AEA) and 2-arachidonoylglycerol (2-AG) are two major eCBs that activate type I cannabinoid receptors (CB1) receptors on the presynaptic neuron in the brain (Di Marzo et al., 1998). Upon stimulation, eCBs are released from postsynaptic neurons and travel across the synaptic cleft to activate CB1 on presynaptic terminals, resulting in depression of synaptic transmission. 


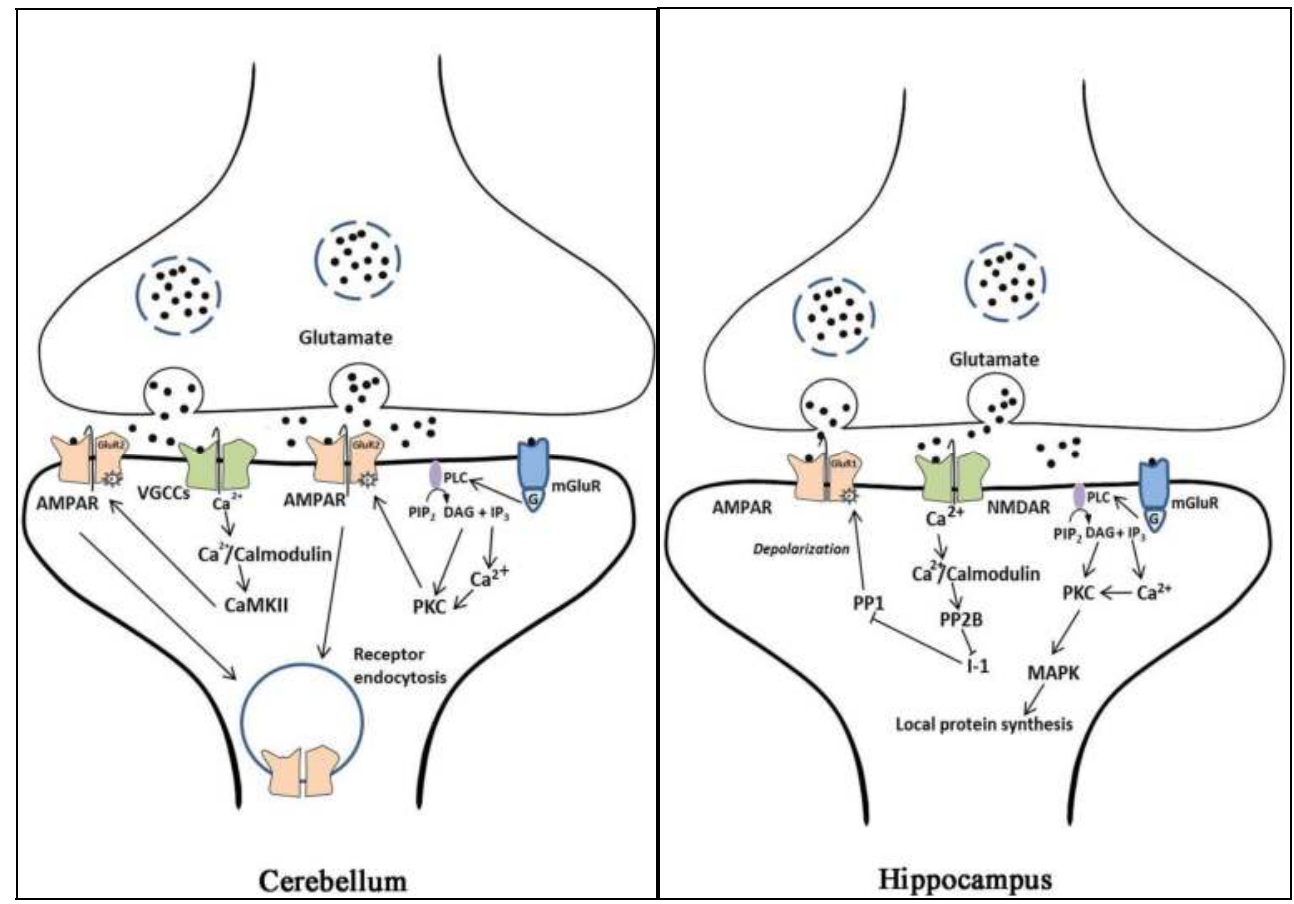

Fig. 6. Mechanisms of LTD induction in hippocampus and cerebellum. Key signaling pathways that lead to LTD in hippocampus and in cerebellum involve AMPAR regulation. Hippocampal LTD involves activation of phosphatases like PP2B and PP1 which dephosphorylate GluR1 resulting in reduced AMPAR conductance, whereas in cerebellum, kinases like CaMKII and PKC are activated resulting in GluR2 phosphorylation and thereby causing AMPAR endocytosis and reduced current.

Of the NMDARs, GluN2B containing NMDARs are supposed to be important for LTD especially in hippocampus as a study using conditional knockout mice showed that the selective ablation of GluN2B subunits in pyramidal neurons in CA1 specifically impairs CA1 NMDAR-LTD. This also results in deficits in several hippocampal dependent learning and memory tasks, providing strong evidence for a key role of this particular from of LTD in memory formation. (Brigman et al., 2010; Collingridge et al., 2010). BDNF is released from glutamatergic neurons in response to high frequency stimulus and is found to have a role in LTP. While BDNF affects synaptic potentiation at hippocampal synapses, proBDNF is involved in LTD. proBDNF, by activating its receptor known as the p75 neurotrophin receptor ( $\left.\mathrm{p} 75^{\mathrm{NTR}}\right)$, facilitates hippocampal (LTD). Deletion of p75NTR-/- in mice selectively impaired the NMDAR dependent LTD, without affecting other forms of synaptic plasticity. p75NTR-/- mice also showed a decrease in the expression of GluN2B, an NMDA receptor subunit uniquely involved in LTD. p75 ${ }^{\mathrm{NTR}-/-}$ mice showed a decrease in the expression of GluN2B in the hippocampus and also a marked reduction in GluN2B-mediated currents at the CA1 synapse. Activation of p75NTR by proBDNF enhanced GluN2B dependent LTD and GluN2B mediated synaptic currents. (Woo et al., 2005). 
The events described above depict the importance of GluN2B subunit in LTD. It is also known that CaMKII can phosphorylate GluN2B at Ser ${ }^{1303}$, both in vitro and in vivo (Omkumar et al., 1996). This phosphorylation prevents the binding of CaMKII to GluN2B in vitro (Strack et al., 2000; O'Leary et al., 2011). Studies from our lab have shown that the phosphorylation status at $\mathrm{Ser}^{1303}$ enables GluN2B to distinguish between the $\mathrm{Ca}^{2+} / \mathrm{CaM}$ activated form and autonomously active Thr ${ }^{286}$-autophosphorylated form of CaMKII. This highlights the need for a dephosphorylation mechanism at GluN2B-Ser ${ }^{1303}$. It has been shown that phosphatases in PSD can dephosphorylate GluN2B-Ser1303 (Rajeevkumar et al., 2009). Although the physiological role of GluN2B-Ser ${ }^{1303}$ is not known to date, it is likely to be involved in LTD mechanism as phosphatases get activated during induction of LTD.

Another major form of LTD worth mentioning is the one which is dependent on group 1 metabotropic glutamate receptors (mGluR). Chemical LTD is typically induced by activation of mGlu receptors. The most commonly induced chemical LTD is by (S)-3, 5dihydroxyphenylglycine (DHPG), an agonist of mGluR, one which is effective even in the absence of $\mathrm{Ca}^{2+}$. Normally mGluR-LTD is induced in CA1 synapses by a train of LFS consisting of single pulses. The mGluR antagonist a-methyl-4-caboxyphenylglycine (MCPG) blocked depotentiation and de novo LTD in CA1 showing the involvement of mGluR in LTD (Bolshakow et al., 1994).

Glutamate binding to mGluR initiates a signaling cascade, involving the breakdown of the membrane lipid PIP2 (Phosphoinositol 4, 5 - bisphosphate) by phospholipase C (PLC) to the important signaling molecules IP3 (Inositol 1, 4, 5 - triphosphate). This also causes release of diacylglycerol (DAG) and calcium mobilization. This leads to the activation of the calcium sensitive kinase, PKC. This enzyme then phosphorylates AMPAR but in such a manner that the conductance is reduced (Bliss et al., 2011). An offshoot is the production of NO, the retrograde messenger. Group I mGluRs (mGluR1/5) activate PLC, leading to $\mathrm{Ca}^{2+}$ mobilization, and activation of the ERK-MAPK pathway through which they modulate signals of synapse-to-nucleus communication and triggers protein synthesis. mGluR1 and mGluR2 receptor subtypes mediate de novo LTD at cerebellar PF-PC synapses and hippocampal mossy fibre synapses respectively.

mGluRs are the critical regulators of activity-dependent protein synthesis in dendrites. Signaling by mGluR1/5 is critical to synaptic circuitry formation during development and is implicated in LTD (Zukin et al., 2009). mGluR1/5 elicit synapse specific modifications in synaptic strength and spine morphology by stimulating rapid local translation of dendritic mRNAs including Fmr1, that encodes fragile X mental retardation protein (FMRP) (Greenough et al., 2001). Expression of mGluR-LTD at Schaffer collateral to CA1 pyramidal cell synapses is mediated by persistent internalization of AMPARs and in adolescent mice requires de novo protein synthesis (Huber et al., 2000; Snyder et al., 2001). But mGluR-LTD at cortical synapses (Desai et al., 2006) requires neither local protein synthesis nor FMRP function. mGluR-LTD is also seen in CA1 in neonates and is protein synthesis dependent. (Nosyreva \& Huber, 2005).

PICK1 is also required for mGluR-LTD at different synapses. mGluRs are associated with protein tyrosine phosphatases rather than Ser/Thr ones. DHPG, a potent agonist of mGluR, induced LTD that involves tyrosine dephosphorylation of GluA2 and is associated with AMPARs endocytosis (Gladding et al., 2009). DHPG-induced LTD appears not to require 
extracellular $\mathrm{Ca}^{2+}$ (Fitzjohn et al., 2001). It also doesn't require CaMKII. Certain other proteins which are activated by mGluRs are arg 3.1(Arc), striatal-enriched protein tyrosine phosphatase (STEP) and microtubule associated protein 1B which are involved in AMPAR internalization (Collingridge et al., 2010).

\subsection{LTD in cerebellum}

Cerebellum is involved in motor learning and non-declarative memory. It is required in the adaptation of vestibulo ocular reflex (VOR) movements of the eyes needed to keep the retinal image stable. In the 1980s, Ito and colleagues provided the first experimental evidence for plasticity in the cerebellar cortex.

Of the three layers of cerebellum; the molecular layer, granular layer and the Purkinje layer, the Purkinje cells synapse on deep cerebellar nuclei which are the major output from the cerebellum (Bear et al., 2001). Purkinje cells modify the output. Purkinje cells receive excitatory input from two sources, viz, climbing fibre (CF) and parallel fibre (PF). Each Purkinje cell receives input from one inferior olive cell (which arises from medulla) via CF and this input is very powerful. This generates a very large EPSP that always strongly activates the postsynaptic Purkinje cells. The other input to the Purkinje cells, viz the PF arises from cerebellar granule (CG) cells. The CG cells in turn receive mossy fibres which arise from precerebellar nuclei. Purkinje cells receive synapses from more than one PF. The plasticity at PF-PC synapse is governed by Marr Albus (Marr, 1969; Albus, 1971) theory which explains the mechanism behind motor learning. It says that the plasticity of the PF synapse is effective if it is active at the same time as the CF input to the Purkinje cell. Activating CF results in massive calcium influx. Despite the large calcium influx, paired CF and PF stimulation results in LTD in Purkinje cells (Ito et al., 1982), whereas PF stimulation alone causes LTP (Lev Ram et al., 2002).

CF stimulation results in large input of EPSP. As a result voltage gated sodium channels open causing massive depolarization. This activates VGCCS, facilitating calcium entry. At the same time, the activation of PF results in glutamate release which binds to AMPA receptor and allows sodium ion entry. Altering AMPAR affects synaptic efficacy by changing the channel density. The other receptor activated is mGluR. It activates the release of downstream second messengers such as DAG and results in activation of PKC. aCaMKII is also activated along with PKC (Hansel, 2006). These kinases can phosphorylate the AMPAR. PKC can phosphorylate GluR2, the subunit of AMPAR at Ser-880 and this brings about receptor endocytosis (Chung et al., 2003). It is a critical event in the induction of cerebellar LTD (Fig. 6). This phosphorylation disrupts the binding of GluR2 to GRIP1 facilitating binding to PICK1 (Xia et al., 2000). Purkinje cells are enriched with GluR2/GluR3 receptors whereas it is poor in expressing GluR1 subunits. Purkinje cells lack NMDAR and thus LTD is mainly AMPAR mediated. The cerebellar LTD is the type of plasticity where information is stored as a decrease in the effectiveness of synaptic connection.

It is interesting to see that the LTP and LTD induction cascades in hippocampus and cerebellar Purkinje synapses are different and exhibit a mirror image like relationship (Jorntell \& Hansel, 2006). As already discussed, LTD in cerebellum, is being brought about by kinases whereas in hippocampus it is brought about by phosphatases. 


\subsection{LTD induction}

LTD can be induced by prolonged periods of LFS by pairing baseline synaptic stimulation with depolarization i.e. normally at a frequency of $10 \mathrm{~Hz}$. LFS of $1 \mathrm{~Hz}$ for 15 minutes brings about LTD in CA1 area of hippocampus of anaesthetized rabbit (Bliss \& Lomo, 1973). This stimulation is preceded by baseline stimulation at frequencies such as $0.1-0.05 \mathrm{~Hz}$ to establish a reference level for basal synaptic transmission. Electrically induced LTD is typically generated by low frequency stimulation (in the range of 1-3 Hz) given for prolonged periods of time (5-15 min) (Braunewell et al., 2001). Coincident EPSPs with action potentials (APs) evokes large calcium signals and leads to LTP whereas unpaired stimulation brings about LTD (Markram et al., 1997). LTD, like LTP possess the characteristics of longevity, input-specificity and associativity. The relative contributions of pre and postsynaptic mechanisms may vary at different times after induction and also across different classes of synapses. In cerebellum, PF-LTD can be induced by paired PF and CF stimulation (Ito et al., 1982), which is typically applied at 1-4 Hz for $5 \mathrm{~min}$.

\subsection{Physiological functions of LTD}

Elucidating the functional role of LTD in vivo has been challenging due to difficulty of inducing it in vivo and due to the lack of selective inhibitors for the same (Collingridge et al., 2010). But still some of the physiological functions of LTD are known.

LTD has been implicated in cerebellar motor learning. For example, studies using PKC transgenic mice showed that chronic PKC inhibition restricted to cerebellar PF-PC synapses exhibited compromised LTD and defective adaptation of VOR. But still a causal relationship remains to be demonstatred between PF-PC LTD and motor learning (De Zeeuw et al., 1998). To the contrary, recent studies using knockout mice which target the expression of PF-PC LTD by blocking internalization of AMPARs show that LTD is not necessary for motor learning. The mutant mice lacked PF-PC LTD but had no difficulty in performing motor learning skills like VOR adaptation, eyeblink conditioning, and locomotion learning on the Erasmus Ladder which covers a wide range of cerebellar learning behaviors (Schonewille et al., 2011).

LTD is implicated in hippocampus dependent learning because of its property of depotentiation. Depotentiation in CA1 and DG has been shown when rats explore a novel environment or a familiar environment containing novel objects. Impairment of reversal learning in water maze was found to be associated with severely impaired hippocampal LTD in dopamine transporter knockout mice. LTD is also involved in learning regarding novelty detection. In freely moving rats, LTD is facilitated during exploration of complex environments containing novel objects (Collingridge et al., 2010).

The various molecular mechanisms involved in LTD in brain have been discussed. LTD has been implicated in several physiological processes including learning and memory and also in development of visual system. Future studies will be focused on the aspects of protein synthesis and turnover involved in LTD in detail. Also the mechanisms by which LTD could be induced by neurotransmitters other than glutamate remains to be elucidated. (Collingridge et al., 2010). 


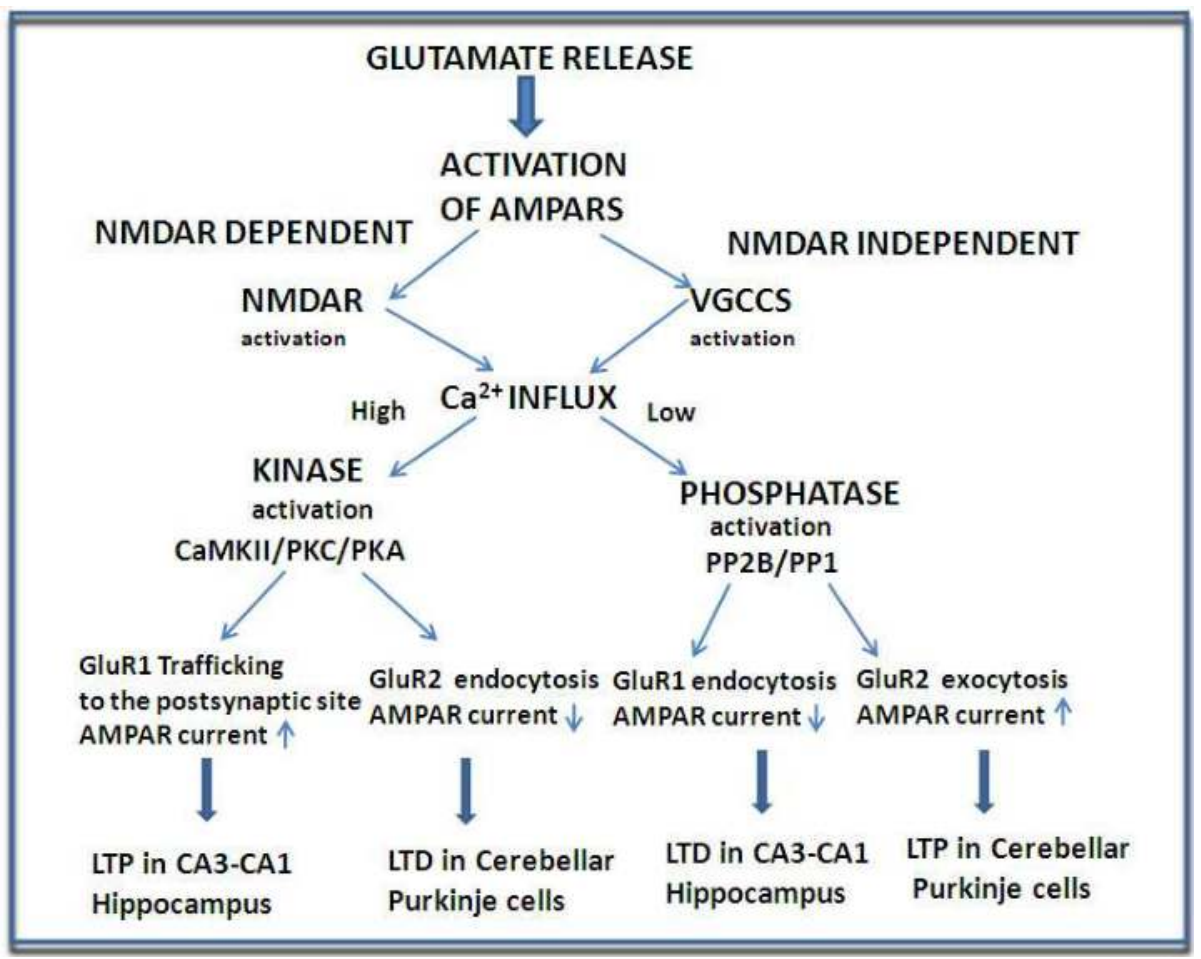

Fig. 7. Scheme of shared post synaptic signaling pathways leading to LTP and LTD

\section{Synaptic plasticity and disease}

In disease conditions, aberrant synaptic plasticity or any defect in signaling mechanism may cause substantial deficits in different aspects of central nervous system. The role of synaptic plasticity in disease is becoming more evident across a wide range of CNS disorders. Understanding the molecular basis of normal and diseased plasticity will provide a platform to study the molecular basis of many of the diseases and to target drugs on plasticity related molecules to treat many of the CNS disorders. Cognitive deficits are the early symptoms that appear much before the onset of neuritic dystrophy and pathology. Often, it is likely that the immediate consequence of aberrant signaling could be impairment of synaptic plasticity. This would later develop into synaptic and neuronal loss. Thus plasticity related mechanisms could have the advantage of being targets for early therapeutic intervention in CNS disorders.

Among the CNS disorders such as Alzheimer's disease (AD), schizophrenia, epilepsy and in disorders associated with learning disabilities where there are alterations of synaptic plasticity, Alzheimer's disease has been extensively studied.

\subsection{Alzheimer's disease}

Hippocampus, amygdala, neocortex, anterior thalamus, entrohinal, and transentrohinal cortices are some of the areas affected in Alzheimers disease (Sweatt, 2010). Synapse loss 
that starts even at early stages of $\mathrm{AD}$, results in a condition where minimum number of synapses are not available for cortical networks and impairment of synaptic plasticity occurs. The neuropathological hallmarks of Alzheimer's disease are the presence of intracellular neurofibrillary tangles (NFT) composed of hyperphosphorylated tau protein and extracellular neuritic plaques composed of amyloid $\beta$ protein (A $\beta$ ) (Montoya, 2011). A $\beta$ is produced by the sequential cleavage of amyloid precursor protein (APP) by $\beta$-secretase and $\gamma$-secretase (Haass \& Selkoe, 1993). 40-residue $A \beta(A \beta 40)$ and 42-residue $A \beta(A \beta 42)$ are the most common isoforms of $A \beta$ (Xia, 2010). Even before plaques could be observed, significant deficits in synaptic transmission have been detected by electrophysiological recordings from the hippocampus of transgenic mice over expressing APP (Hsia et al., 1999; Mucke et al., 2000). Thus aberrations in synaptic function are the early events followed by the formation of plaques and NFT (Funato et al., 1999; Hartl et al., 2008; Selkoe, 2002; Walsh \& Selkoe, 2004, as cited in Proctor et al., 2011).

\subsubsection{Disruption of the plasticity of glutamatergic synaptic transmission}

The alterations of synaptic plasticity which happens before synaptic loss may be initiating neurodegeneration. The spatial working memory and LTP were normal in young $\mathrm{APP}_{695} \mathrm{SWE}$ transgenic mice. There was reduction in LTP and deficits in behavioural performance with aged transgenic mice. The deterioration of LTP in dentate gyrus and CA1 and behavioural deficit appear in a correlated manner (Chapman et al., 1999). A $\beta$ concentrations increased with age. Many lines of investigations show that oligomeric forms of A $\beta$ species interfere with synaptic plasticity, inhibit LTP and impairs maintenance of LTP (Barghorn et al., 2005; Klyubin et al., 2008; Shankar et al., 2008; Walsh et al., 2002; Wang et al., 2002; Stephan et al., 2001). A $\beta$ peptide when applied before and during HFS inhibits LTP induction in the dentate medial perforant path and Schaffer colllateral-CA1 pathway (Chen et al., 2000; Chen et al., 2002). The basal synaptic transmission or short-term synaptic plasticity remained intact. A $\beta$ inhibits maintenance phase of L-LTP and also inhibits protein synthesis in the L-LTP phase when applied after HFS. The effects of A $\beta$ on the induction of LTP and on L-LTP are independent of each other, working through multiple mechanisms (Chen et al., 2002). Different forms of LTP affected by A $\beta$ will be reflected as deficits in different phases of memory and also at a concentration of $A \beta$, below that is required to produce neurotoxicity (Chen et al., 2002).

\subsubsection{Molecular events causing disruption of LTP}

$\mathrm{A} \beta$ was shown to increase intracellular $\mathrm{Ca}^{2+}$ concentrations due to potentiation of currents through L-type $\mathrm{Ca}^{2+}$ channels (Ueda et al., 1997) and blockade of fast-inactivating $\mathrm{K}^{+}$ channels that leads to prolonged membrane depolarization and $\mathrm{Ca}^{2+}$ influx (Good et al., 1996). Basal synaptic transmission and NMDAR-dependent forms of LTP are impaired in the aging hippocampus (Foster \& Norris, 1997), which correlates with deficits in spatial memory (Barnes \& McNaughton, 1985; Diana et al., 1995). A $\beta$ induced $\mathrm{Ca}^{2+}$ transients activate calcineurin and cause desensitization of NMDAR channels, reducing $\mathrm{Ca}^{2+}$ influx through these channels during LTP-inducing stimulus protocol. As a result induction of NMDAR-dependent forms of LTP, E-LTP and also L-LTP are suppressed (Chen et al., 2002). $\mathrm{A} \beta$ also inhibited NMDAR mediated EPSCs. Activated calcineurin could impair the mechanisms underlying the components of L-LTP and long-term memory. This could be 
related to early signs of memory deficits of $\mathrm{AD}$. Under the influence of $\mathrm{A} \beta$ oligomers, activation of ERK, MAPK, CaMKII and Akt/PKB were reduced during LTP (Selkoe, 2008; Zeng et al., 2010). In Alzheimer's disease mouse models, erratic regulation of Arc expression leads to synaptic dysfunction (Shepherd \& Bear, 2011).

NMDAR dependent neocortical plasticity deficits were observed in AD patients (Battaglia et al., 2007). Nanomolar concentrations of $A \beta$ reduced the NMDAR-mediated EPSCs in hippocampal slices ( $\mathrm{Li}$ et al., 2009; Cerpa et al., 2010, as cited in $\mathrm{Hu}$ et al., 2011). In APP transgenic mice, there is lower level of cell surface NMDA receptors. Hence, A $\beta$ peptide may be promoting the endocytosis of NMDA receptors. NMDA receptor endocytosis also requires a-7-nicotinic receptors (nAChRs), PP2B and the STEP tyrosine phosphatase. Autopsy tissues of $A D$ patients show a reduction in the NMDAR subunit levels. PP2B is activated, when A $\beta$ oligomers bind and activate a-7-nicotinic receptors. Tyrosine phosphatase STEP is activated by PP2B-mediated dephosphorylation. Dephosphorylation of Y1472 of GluN2B by the activated STEP removes NMDAR from surface. In both AD transgenic mouse models and in the brains of AD subjects increased levels of STEP were detected (Chin et al., 2005; Kurup et al., 2010, as cited in Proctor et al., 2011). A $\beta$ induced changes in LTP could be due to disruption of plasticity mechanism as a result of NMDAR changes. Postsynaptic protein tyrosine kinase EphB2, a regulator of NMDAR trafficking, is cleaved on binding to $A \beta$ and this promotes the removal of synaptic NMDARs (Cissé et al., 2011). Stimulation of inducible nitric oxide synthase (iNOS), superoxide production and activation of microglia, all by A $\beta$, may also inhibit NMDAR dependent LTP (Wang et al., 2004). The density of dendritic spines decrease and the active synapses are reduced when exposed to physiological concentration of $A \beta$. Electrophysiological experiments show that decrease in spine density can be correlated to the loss of excitatory synapses (Selkoe, 2008). A $\beta$ requires the activity of NMDA receptors to bring about morphological changes of the dendrite (Shankar et al., 2007).

An increase in $A \beta$ concentration can decrease AMPA receptor-mediated EPSCs or field EPSPs. A $\beta$ binds to GluA2 containing AMPA receptors and causes the endocytosis of AMPARs in a clathrin-dependent, calcineurin and densin mediated pathway (Liu et al., 2010, as cited in Hu et al., 2011). High concentrations of A $\beta$ also induce phosphorylation of GluA2-Ser 880 by PKC and subsequent internalization of the receptor. Caspase- 3 cleavage of calcineurin facilitates postsynaptic GluA1 dephosphorylation and internalization in the cultured hippocampal neurons from transgenic mouse. This observation was supplemented by hippocampal-dependent contextual fear conditioning (CFC) deficit shown by transgenic $\mathrm{AD}$ mouse model and an alteration in basic glutamatergic synaptic transmission and enhanced LTD. The reduced AMPAR-mediated currents are associated with the lower number of AMPAR at the synapse (D'Amelio et al., 2011). The trafficking and anchoring of AMPA and NMDA receptors are disturbed by hyperphosphorylated tau also (Hoover et al., 2010, as cited in Hu et al., 2011).

$\mathrm{A} \beta$ is found to be attached to hippocampal neurons and its presence could be seen on dendritic surfaces (Gong et al., 2003). Synapse elimination associated with decrease in size of the synapse can be linked with degradation of the PSD proteinaceous network (Gong \& Lippa, 2010). The number and compartmentalization of NMDA and AMPA receptors in PSD are determined by PSD-95, and other scaffolding proteins. PSD-95 and SAP102 are found to be altered in the susceptible regions of AD brain (Gylys et al., 2004; Leuba et al., 2008a, 2008b, as cited in Proctor et al., 2011). The lower levels of NMDA and AMPA 
receptors can be due to the depletion of PSD-95 from PSD, altering interactions between glutamate receptors and scaffolding proteins. This could possibly be one of the mechanisms leading to the disruption of LTP. AMPA receptors are removed from the synapse by binding to scaffolding protein AKAP-150 and PSD-95 (Bhattacharyya et al., 2009, as cited in Proctor et al., 2011) as seen in LTD. In APP transgenic mouse model loss of AMPARs are seen. The changes in LTP, integrity of spine and reduced NMDAR expression could all be due to the $A \beta$ induced disruption in AMPAR trafficking and expression, as AMPAR regulation is important for NMDAR-dependent LTP (Proctor et al., 2011).

Elevated $A \beta$ blocks neuronal glutamate uptake at synapse, the outcome of which is an increased glutamate at synaptic cleft (Li et al., 2009). This may lead to the activation of extra or perisynaptic NMDAR promoting LTD. The activation of perisynaptic mGluRs may also be involved in the facilitation of LTD by A $\beta$. The pathway for A $\beta$ induced LTD induction involves an initial synaptic activation of NMDAR by glutamate followed by synaptic NMDAR desensitization, NMDAR and AMPAR internalization, and activation of perisynaptic NMDARs and mGluRs (Hsieh et al., 2006; Li et al., 2009, as cited in Palop and Mucke, 2010). In patients with Alzheimer's disease, glycogen synthase kinase (GSK3 $\beta$ ) deregulation due to its increased expression causes reactivation of NMDAR-LTD, which leads to synaptic loss (Collingridge et al., 2010). Hence A $\beta$ induced LTP deficits seem to depend on activation of LTD pathways.

In the dentate gyrus, at medial perforant path synapses on the dentate granule cells, pairedpulse facilitation (PPF) and LTP are impaired in mouse transgenic model of AD (Palop et al., 2007; Harris et al., 2010). Tau reduction eliminates abnormalities in synaptic transmission and plasticity in hippocampal subfields of hAPPJ20 mice (Palop et al., 2007; Harris et al., 2010; Roberson et al., 2011). Phosphorylation of tau by GSK3 modulates the pathway by which A $\beta$ exerts its pathogenic downstream effects on LTP. This is similar to the A $\beta$ mediated neurodegeneration (Tackenberg \& Brandt, 2009). The absence of tau prevents the synaptic dysfunction induced by A $\beta$ (Shipton et al., 2011).

\subsection{Synaptic plasticity and other diseases}

Other diseases conditions where impairments in synaptic plasticity were observed are schizophrenia, Fragile X Syndrome (Lauterborn et al., 2007; Connor et al., 2011, as cited in Kumar, 2011), Parkinson's disease (Bagetta et al., 2010, as cited in Kumar, 2011), Down syndrome (Costa and Grybko, 2005; Siarey et al., 2005, as cited in Kumar, 2011), Rett syndrome (Moretti et al., 2006; Weng et al., 2011, as cited in Kumar, 2011), Huntington's disease (Usdin et al., 1999; Murphy et al., 2000; Lynch et al., 2007, as cited in Kumar, 2011), Niemann-Pick disease type C (Zhou et al., 2011, as cited in Kumar, 2011), Rubinstein-Taybi syndrome (Alarcon et al., 2004, as cited in Kumar, 2011), brain inflammation (Min et al., 2009; Lynch, 2010, as cited in Kumar, 2011), glioma (Wang et al., 2010, as cited in Kumar, 2011) and diabetes (Biessels et al., 1996; Kamal et al., 1999, 2000, 2005; Valastro et al., 2002; Artola et al., 2005; Artola, 2008, as cited in Kumar, 2011).

Schizophrenia is caused by abnormal synaptic regulation. Six genes identified for schizophrenia (Harrison \& Weinberger, 2005) encode for proteins involved in synaptic plasticity and its modulation (Stephan, 2006). Neurophysiological studies have reported in 
vivo disturbances of cortical plasticity and excitability in schizophrenia patients. Paired associative stimulation (PAS) induced LTP-like plasticity was disrupted and these plasticity deficits were indicated to be caused by NMDAR abnormalities in schizophrenia patients (Frantseva et al., 2008). Dysfunction of glutamatergic transmission is associated with the pathophysiological state in schizophrenia and this will lead to disturbed plasticity and neurotoxicity (Hasan et al., 2011; Konradi and Heckers, 2003; Paz, 2008).

Hippocampal LTP in CA1 area was greatly reduced in epilepsy. This reduction was associated with altered dendritic morphology and reduced hippocampal non-spatial memory seen in epileptic mouse model (Sgobio et al., 2010). The composition of ionotropic glutamate receptors in the PSD was found to be altered in brain areas where seizure activity is more pronounced (Wyneken et al., 2003). Application of low frequency stimulation to depoteniate the hyperexcitable synapses were found to be effective in epileptic patients (Tergau et al., 1999).

In drug addiction and fear conditioning related to post traumatic stress disorder, normal LTP and learning are responsible for the undesired condition (Mahan and Ressler, 2011). The impairment of hippocampus-dependent memory retrieval under acute stress condition is mediated by hippocampal LTD (Collingridge et al., 2010). In Fragile X syndrome (FXS), FMRP, is mutated and acts as a negative regulator of Arc translation. The dysregulated expression of Arc may alter plasticity (Shepherd \& Bear, 2011).

A plethora of information thus provide concrete evidence that impairment of synaptic plasticity in diseases can contribute to decline in learning and memory.

\section{Conclusion}

Although a great deal has been learnt regarding the mechanisms that operate during synaptic plasticity, a complete description of the molecular basis of synaptic plasticity that underlies higher brain functions such as learning and memory is yet to be accomplished. While there is strong experimental support for changes in AMPAR activity as a major post synaptic mechanism supporting plasticity at synapses, the role of presynaptic mechanisms is less understood. The diversity in the mechanisms across different brain regions and across different species is a major challenge towards providing a mechanistic explanation of synaptic plasticity. Understanding the deviations in synaptic plasticity mechanisms in diseases may reveal new targets for the early therapeutic intervention in CNS disorders.

\section{References}

Abraham, W. C., Logan, B., Greenwood, J. M. \& Dragunow, M. (2002). Induction and experience-dependent consolidation of stable long-term potentiation lasting months in the hippocampus. J. Neurosci., Vol.22, No.21, pp. 9626-34.

Abraham, W. C., Logan, B., Wolf, A. \& Benuskova, L. (2007). "Heterosynaptic" LTD in the Dentate Gyrus of Anesthetized Rat Requires Homosynaptic Activity. J. Neurophysiol., Vol.98, pp. 1048-1051.

Albus, J. S. (1971). A theory of cerebellar function. Math. Biosci. Vol.10, pp. 25-61.

Aniksztejn, L. \& Ben-Ari, Y. (1991). Novel form of long-term potentiation produced by a K+ channel blocker in the hippocampus. Nature, Vol.349, No.6304, pp. 67-9. 
Anwyl, R. (2009). Metabotropic glutamate receptor-dependent long-term potentiation. Neuropharmacology, Vol.56, No. 4, pp.735-40.

Barghorn, S., Nimmrich, V., Striebinger, A., Krantz, C., Keller, P., Janson, B., Bahr, M., Schmidt, M., Bitner, R. S, Harlan, J., Barlow, E., Ebert, U. \& Hillen, H. (2005). Globular amyloid beta-peptide oligomer-a homogenous and stable neuropathological protein in Alzheimer's disease. J. Neurochem., Vol.95, pp834-847.

Barnes, C. A. \& McNaughton, B. L. (1985). An age comparison of the rates of acquisition and forgetting spatial information in relation to long-term enhancement of hippocampal synapses. Behavioral Neuroscience, Vol.99, pp. 1040-1048.

Barria, A. \& Malinow, R. (2005). NMDA receptor subunit composition controls synaptic plasticity by regulating binding to CaMKII. Neuron,Vol.48, pp. 289-301.

Barria, A., Muller, D., Derkach, V., Griffith, L. C. \& Soderling, T. R. (1997b). Regulatory phosphorylation of AMPA-type glutamate receptors by CaM-KII during long-term potentiation. Science, Vol.276, No.5321, pp. 2042-5.

Bashir, Z. I., Jane, D. E., Sunter, D. C., Watkins, J. C. \& Collingridge, G. L. (1993). Metabotropic glutamate receptors contribute to the induction of long-term depression in the CA1 region of the hippocampus. Eur. J. Parmacol., Vol.239, No.1-3, pp. 265-6.

Bastrikova, N., Gardner, G. A., Reece, J. M., Jeromin, A. \& Dudek, S. M. (2008). Synapse elimination accompanies functional plasticity in hippocampal neurons. Proc. Natl. Acad. Sci., U S A., Vol.105, pp. 3123-3127.

Battaglia, F., Wang, H. Y., Ghilardi, M. F., Gashi, E., Quartarone, A., Friedman, E. \& Nixon, R. A. (2007). Cortical plasticity in Alzheimer's disease in humans and rodents. Biol. Psychiatr., Vol.62, pp. 1405-1412, ISSN 0006-3223.

Bear, M. F., Connors, B. W. \& Paradiso, M. A. (2001). Neuroscience Exploring the Brain, (second edition), Lippincott, Williams and Wilkins, 0-683-30596-4, USA.

Beattie, E. C., Carroll, R. C., Yu, X., Morishita, W., Yasuda, H., von Zastrow, M. \& Malenka, R.C. (2000). Regulation of AMPA receptor endocytosis by a signaling mechanism shared with LTD. Nat. Neurosci., Vol.3, pp. 1291-1300.

Becker, N., Wierenga, C. J., Fonseca, R., Bonhoeffer, T. \& Nägerl, U. V. (2008). LTD induction causes morphological changes of presynaptic boutons and reduces their contacts with spines. Neuron, Vol.60, pp. 590-597.

Bhattacharya, S., Biou, V., Xu, W., Shluter, O. \& Malenka, R. C. (2009). A critical role for PSD-95/AKAP interactions in endocytosis of synaptic AMPA receptors. Nat. Neurosci., Vol.12, Issue 2, pp. 172-181.

Bienestock, E. L., Cooper, L. N. \& Munro, P. W. (1982). Theory for the development of neuron selectivity: orientation specificity and binocular interaction in visual cortex. J. Neurosci., Vol.2, pp .32-48.

Bliss, T. V. (1990). Long-term potentiation. Science, Vol.249, No.4972, pp. 973.

Bliss, T. V. \& Cooke, S. F. (2011). Long-term potentiation and long-term depression: a clinical perspective. Clinics, Vol.66(S1), pp. 3-17.

Bliss, T. V. \& Collingridge, G. L. (1993). A synaptic model of memory: Long-term potentiation in the hippocampus. Nature, Vol.361, No.6407, pp. 31-9. 
Bliss, T. V. \& Lomo, T. (1973). Long-lasting potentiation of synaptic transmission in the dentate area of the anaesthetized rabbit following stimulation of the perforant path. J. Physiol., Vol.232, No.2, pp. 331-56.

Blundon, J. A. \& Zakharenko, S. S. (2008). Dissecting the components of long-term potentiation. Neuroscientist, Vol.14, No.6, pp. 598-608.

Bolshakow, V. Y \& Siegelbaum, S. A. (1994). Postsynaptic induction and presynaptic expression of hippocampal long term depression. Science, Vol.264, pp. 1148-1152.

Bramham, C. R., Alme, M. N., Bittins, M., Kuipers, S. D., Nair, R. R., Pai, B., Panja, D., Schubert, M. \& Soule, J. (2010). The Arc of synaptic memory. Exp. Brain Res, Vol.200, pp. 125-140.

Braunewell, K. H. \& Manahan-Vaughan, D. (2001). Long-term depression: a cellular basis for learning? Rev. Neurosci., Vol.12, pp. 121-140.

Brigman, J. L., Wright, T., Talani, G., Mulcare, S. P., Jinde, S., Seabold, G. K., Mathu, P., Davis, M. I., Bock, R., Gustin, R. M., Colbran, R. J., Alvarez, V. A., Nakazawa, K., Delpire, E., Lovinger, D. M. \& Holmes,A. (2010). Loss of GluN2B-Containing NMDA Receptors in CA1 Hippocampus and Cortex Impairs Long-Term Depression, Reduces Dendritic Spine Density, and Disrupts Learning. J. Neurosci., Vol.30, No.13, pp. 4590-4600.

Bryne, J. H. \& Roberts, J. L. (2009). From Molecules to Networks, An Introduction to Cellular and Molecular Neuroscience, (Ed.2). Elsevier, ISBN 978-0-12-374132-5, China.

Chapman, P. F., White, G. L., Jones, M. W., Cooper-Blacketer, D., Marshall, V. J., Irizarry, M., Younkin, L., Good, M. A., Bliss, T. V. P. \& Hyman, B. T. (1999). Impaired synaptic plasticity and learning in aged amyloid precursor protein transgenic mice. Nat. Neurosci., Vol.12, pp. 271-276.

Chen, Q. S., Kagan, B. L., Hirakura, Y. \& Xie, C. W. (2000). Impairment of hippocampal longterm potentiation by Alzheimer amyloid beta-peptides. Journal of Neuroscience Research, Vol.60, pp. 65-72.

Chen, Q. S., Wei, W. Z., Shimahara, T. \& Xie, C. W. (2002). Alzheimer amyloid beta peptide inhibits the late phase of long-term potentiation through calcineurin-dependent mechanisms in the hippocampal dentate gyrus. Neurobiol. Learn. Mem., Vol.77, pp. $354-371$.

Cheriyan, J., Kumar, P., Mayadevi, M., Surolia, A. \& Omkumar, R. V. (2011). Calcium/calmodulin dependent protein kinase II bound to NMDA receptor 2B subunit exhibits increased ATP affinity and attenuated dephosphorylation. PLoS One, Vol.6, e16495.

Chung, H. J., Steinberg, J. P., Huganhir, R. L. \& Linden, D. J. (2003). Requirement of AMPA receptor GluR2 phosphorylation for cerebellar long term depression. Science, Vol.300, pp. 1751-1755.

Cissé, M., B., Halabisky, J., Harris, N., Devidze, D. B., Dubal, B., Sun, A., Orr, G., Lotz, D. H., Kim \& Hamto, P. (2011). Reversing EphB2 depletion rescues cognitive functions in Alzheimer model. Nature, Vol.469, pp. 47-52.

Collingridge, G. L., Peineau, S., Howland, J. G. \& Wang, Y. T. (2010). Long-term depression in the CNS, Nature Neurosci., Vol.11, pp. 459-473.

Cooke, S. F. \& Bliss, T. V. (2006). Plasticity in the human central nervous system. Brain, Vol.129, No.Pt 7, pp. 1659-73. 
D'Amelio, M., Cavallucci, V., Middei, S., Marchetti, C., Pacioni ,S., Ferri ,A., Diamantini, A., De Zio, D., Carrara, P., Battistini, L, Moreno, S., Bacci, A., Ammassari-Teule, M., Marie, H. \& Cecconi, F. (2011). Caspase-3 triggers early synaptic dysfunction in a mouse model of Alzheimer's disease. Nature Neuroscience, Vol.14, pp. 69-76.

De Zeeuw, C. I., Hansel, C., Bian, F., Koekkoek, S. K. E., van Alphen, A. M, Linden D. J. \& Oberdick, J. (1998). Expression of a Protein Kinase C Inhibitor in Purkinje Cells Blocks Cerebellar LTD and Adaptation of the vestibulo-Ocular Reflex. Neuron, Vol.20, pp. 495-508.

Derkach, V., Barria, A. \& Soderling, T. R. (1999). Ca ${ }^{2+} /$ calmodulin-kinase II enhances channel conductance of alpha-amino-3-hydroxy-5-methyl-4-isoxazolepropionate type glutamate receptors. Proc. Natl. Acad. Sci. U S A, Vol.96, No.6, pp. 3269-74.

Desai, N. S., Casimiro, T. M., Gruber, S. M. \& Vanderklish, P. W. (2006). Early postnatal plasticity in neocortex of Fmr1 knockout mice. J. Neurophysiol., Vol.96, pp. 17341745 .

Di Marzo, V., Melck, D., Bisogno, T. \& De Petrocellis, L. (1998). Endocannabinoids: endogenous cannabinoid receptor ligands with neuromodulatory action. Trends Neurosci., Vol.21, pp. 521-528.

Diana, G., Domenici, M. R., Scotti de Carolis, A., Loizzo, A. \& Sagratella, S. (1995). Reduced hippocampal CA1 $\mathrm{Ca}\left({ }^{2+}\right)$-induced long-term potentiation is associated with agedependent impairment of spatial learning. Brain Research, Vol.686, pp. 107-110.

Doyle, M. \& Kiebler, M. A. (2011). Mechanisms of dendritic mRNA transport and its role in synaptic tagging. The EMBO J., Vol.30, pp. 3540-3552.

Fitzjohn, S. M., Palmer, M. J., May, J. E. R., Neeson, A., Morris, S. A. C. \& Collingridge, G. L. (2001). A characterization of long-term depression induced by metabotropic glutamate receptor activation in the rat hippocampus in vitro. J. Physiol., Vol.537.2, pp. 421-430.

Foster, T. C., \& Norris, C. M. (1997). Age-associated changes in Ca (2+)-dependent processes: Relation to hippocampal synaptic plasticity. Hippocampus, Vol.7, pp. 602-612.

Frey, U., Huang, Y. Y. \& Kandel, E. R. (1993). Effects of cAMP simulate a late stage of LTP in hippocampal CA1 neurons. Science, Vol.260, No.5114, pp. 1661-4.

Gladding C. M. (2009). Tyrosine dephosphorylation regulates AMPAR internalization in mGluR LTD. Mol. Cell. Neurosci., Vol.40, pp. 267-279.

Good, T. A., Smith, D. O. \& Murphy, R. M. (1996). Beta-amyloid peptide blocks the fastinactivating $\mathrm{K}+$ current in rat hippocampal neurons. Biophysical Journal, Vol.70, pp. 296-304

Gong, Y., Chang, L., Viola, K. L., Lacor, P. N., Lambert, M. P., Finch, C. E., Krafft, G. A. \& Klein, W. L. (2003). Alzheimer's disease-affected brain: presence of oligomeric A beta ligands (ADDLs) suggests a molecular basis for reversible memory loss. Proc. Natl. Acad. Sci. U S A., Vol.100, No.18, pp. 10417-10422.

Gong, Y. \& Lippa, C. F. (2010). Review: Disruption of the Postsynaptic Density in Alzheimerâs Disease and Other Neurodegenerative Dementias. American journal of Alzheimer's disease and other dementias, Vol.25, pp. 547-555.

Greenough, W. T., Klintsova, A. Y., Irwin, S. A., Galvez, R., Bates, K. E. \& Weiler, I. J. (2001). Synaptic regulation of protein synthesis and the fragile $\mathrm{X}$ protein. Proc. Natl. Acad. Sci. U.S.A Vol.98, pp. 7101-7106. 
Haass, C. \& Selkoe, D. J. (1993). Cellular processing of beta-amyloid precursor protein and the genesis of amyloid beta-peptide. Cell., Dec 17, Vol.75, No.6, pp.1 039-42.

Hansel C., de Jeu. M., Belmeguenai. A., Houtman S. H., Buitendijk G. H. S, Andreev, D., De Zeeuw, C. I. \& Elgersma Y. (2006). aCaMKII is Essential for Cerebellar LTD and motor learning, Neuron, Vol.51, pp. 835-843.

Harris, J. A., Devidze, N., Halabisky, B., Lo, I., Thwin, M.T., Yu, G. Q., Bredesen, D. E., Masliah, E. \& Mucke, L. (2010). Many neuronal and behavioral impairments in transgenic mouse models of Alzheimer's disease are independent of caspase cleavage of the amyloid precursor protein. J. Neurosci., Vol.30, No.1, pp. 372-381, ISSN 0270-6474.

Harrison, P. J. \& Weinberger, D. R . (2005). Schizophrenia genes, gene expression and neuropathology: On the matter of their convergence. Mol. Psychiatry, Vol.10, pp. 40-68, ISSN 1359-4184.

Hasan, A., Michael, A., Nitscheb, Reina, N., Schneider-Axmanna, T., Gusea, B., Grubera, O., Falkaia, P. \& Wobrocka, T. (2011). Dysfunctional long-term potentiation-like plasticity in schizophrenia revealed by transcranial direct current stimulation. Behavioural Brain Research, Vol.224, pp. 15- 22, ISSN 0166-4328.

Hebb, D. (1949). The organization of behavior, pp. 319-340.

Hsia, A. Y., Masliah, E., McConlogue, L., Yu, G. Q, Tatsuno, G., Hu, K., Kholodenko, D., Malenka, R. C., Nicoll, R. A. \& Mucke L. (1999). Plaque-independent disruption of neural circuits in Alzheimer's disease mouse models, Proc. Natl. Acad. Sci. U S A., Vol.96, No6, pp. 3228-3233.

Hu, G. Y., Hvalby, O., Walaas, S. I., Albert, K. A., Skjeflo, P., Andersen, P. \& Greengard, P. (1987). Protein kinase C injection into hippocampal pyramidal cells elicits features of long term potentiation. Nature, Vol.328, No 6129, pp. 426-9.

$\mathrm{Hu}$, N. W., Ondrejcak, T. \& Rowan, M. J. (2011). Glutamate receptors in preclinical research on Alzheimer's disease: update on recent advances. Pharmacology Biochemistry and Behavior, ISSN 0091-3057.

Huang, Y. Y. \& Kandel, E. R. (1994). Recruitment of long-lasting and protein kinase adependent long-term potentiation in the CA1 region of hippocampus requires repeated tetanization. Learn. Mem., Vol.1, No.1, pp. 74-82.

Huber, K. M., Kayser, M. S. \& Bear, M. F. (2000). Role for rapid dendritic protein synthesis in hippocampal mGluR dependent long-term depression. Science, Vol.288, pp. 12541257.

Ito, M. (1982). Cerebellar control of the vestibule ocular reflex around the flocculus hypothesis. Annu. Rev. Neurosci., Vol.5, pp. 275-296.

Jorntell, H. \& Hansel, C. (2006). Synaptic memories upside down: Bidirectional plasticity at cerebellar parallel fiber-purkinje cell synapses. Neuron, Vol.52, No.2, pp. 227-38, ISSN 0959-4388.

Kandel, E. R. (2001). The molecular biology of memory storage: A dialogue between genes and synapses. Science, Vol.294, No.5544, pp. 1030-8.

Kandel, E. R., Schwartz, J. H. \& Jessel, T. M. (2000). Principles of Neural Science. (Ed.4). McGraw-Hill, ISBN 0-8385-7701-6. 
Kemp, A. \& Manahan-Vaughan, D. (2007). Hippocampal long-term depression: master or minion in declarative memory processes? TRENDS in Neurosciences, Vol.30 No.3, pp. 111-118.

Kim, M. J., Futai, K., Jo, J., Hayashi, Y., Cho, K. \& Sheng, M. (2007). Synaptic Accumulation of PSD-95 and Synaptic Function Regulated by Phosphorylation of Serine-295 of PSD-95. Neuron, Vol.56, pp. 488-502

Klyubin, I., Betts, V., Welzel, A. T., Blennow, K., Zetterberg, H., Wallin, A., Lemere, C. A. , Cullen, W. K., Peng, Y., Wisniewski, T., Selkoe, D. J., Anwyl, R., Walsh, D. M. \& Rowan, M. J. (2008). Amyloid beta protein dimer-containing human CSF disrupts synaptic plasticity: prevention by systemic passive immunization. J. Neurosci., Vol. 28, No.16, pp. 4231-7, ISSN 0270-6474/08/284231-07.

Konradi, C. \& Heckers, S. (2003). Molecular aspects of glutamate dysregulation: implications for schizophrenia and its treatment. Pharmacol. Ther., Vol.97, pp. 153-79, ISSN 01637258.

Kullmann, D. M. \& Lamsa, K. (2008). Roles of distinct glutamate receptors in induction of anti-hebbian long-term potentiation. J. Physiol, Vol.586, No.6, pp. 1481-6.

Kumar, A. (2011). Long-term potentiation at CA3-CA1 hippocampal synapses with special emphasis on aging, disease, and stress. Front. Ag. Neurosci., Vol3, Article 7, doi: 10.3389/fnagi.2011.00007

Lamprecht, R. \& LeDoux, J. (2004). Structural plasticity and memory. Nature Reviews Neuroscience, Vol.5, pp. 45-54.

Lamsa, K. P., Heeroma, J. H., Somogyi, P., Rusakov, D. A. \& Kullmann, D. M. (2007). Antihebbian long-term potentiation in the hippocampal feedback inhibitory circuit. Science, Vol.315, No.5816, pp. 1262-6.

Lee, H. K., Barbaroise, M., Kameyama, K., Bear, M. F. \& Huganhir, R. L. (2000). Regulation of distinct AMPA receptor phosphorylation sites during bidirectional synaptic plasticity. Nature, Vol.405, pp. 955-959.

Lev- Ram, V., Wong, S. T., Storm, D. R. \& Tsein, R. Y. (2002). A new form of cerebellar long term potentiation is postsynaptic and depends on nitric oxide but not cAMP. Proc. Natl. Acad. Sci. USA., Vol 99, pp. 8389-8393.

Levy, W. B. \& Steward, O. (1979). Synapses as associative memory elements in the hippocampal formation. Brain Res., Vol.175, No.2, pp. 233-45.

Li, S., Hong, S., Shepardson, N. E., Walsh, D.M., Shankar, G. M. \& Selkoe, D. (2009). Soluble oligomers of amyloid $\beta$ protein facilitate hippocampal long-term depression by disrupting neuronal glutamate uptake. Neuron, Vol.62, No6, pp. 788-801.

Lisman, J., Grace, A. A. \& Duzel, E. (2011). A neohebbian framework for episodic memory; role of dopamine-dependent late LTP. Trends in Neurosciences.

Lisman, J., Schulman, H. \& Cline, H. ( 2002). The molecular basis of CaMKII function in synaptic and behavioural memory. Nat. Rev. Neurosci., Vol.3, pp.1 75-190.

Lu, J. T., Li, C. Y., Zhao, J. P., Poo, M. M. \& Zhang, X. H. (2007). Spike-timing-dependent plasticity of neocortical excitatory synapses on inhibitory interneurons depends on target cell type. J. Neurosci., Vol.27, No.36, pp. 9711-20.

Lu,Y., Ji,Y., Ganeshan, S., Schloesser, R., Martinowich, K., Sun, M., Mei, F., Chao, M, V. \& Lu, B. (2011) TrkB as a Potential Synaptic and Behavioral Tag. The journal of Neuroscience, Vol.31(33), pp. 11762-11771. 
Mahan, A. L. \& Ressler, K. J. (2011). Fear conditioning, synaptic plasticity and the amygdala: implications for post traumatic stress disorder, Trends in Neurosciences,(Article in press), ISSN 0166-2236

Malenka, R. C. \& Bear, M. F. (2004). LTP and LTD: An embarrassment of riches. Neuron, Vol.44, No(1), pp. 5-21.

Malenka, R. C. (2002). Synaptic plasticity. Neuropsychopharmacology: The Fifth Generation of Progress, pp. 147-157.

Malenka, R. C. (2003). The long-term potential of LTP. Nat. Rev. Neurosci., Vol.4, No.11, pp. 923-6.

Markram, H. (1997). Regulation of Synaptic Efficacy by Coincidence of Postsynaptic APs and EPSPs. Science, Vol.275, pp. 213.

Marr, D. (1969). Theory of cerebellar cortex. J. Physiol., Vol.202, pp. 437-455.

Martin, S. J., Grimwood, P. D. \& Morris, R. G. (2000). Synaptic plasticity and memory: An evaluation of the hypothesis. Annu. Rev. Neurosci., Vol.23, pp. 649-711.

Molnar, E. (2011). Long-term potentiation in cultured hippocampal neurons. Seminars in Cell and Developmental Biology, article in press, ISSN 1084-9521

Montoya, D. A. C. (2011). Synaptic plasticity in Alzheimer's disease: Toward early detection using non-invasive protocols. Rev. Neurocience. (Article in press).

Moosmang, S., Haider, N., Klugbauer, N., Adelsberger, H., Langwieser, N., Muller, J., Stiess, M., Marais, E., Schulla, V., Lacinova, L., Goebbels, S., Nave, K. A., Storm, D. R., Hofmann, F. \& Kleppisch, T. (2005). Role of hippocampal Cav1.2 $\mathrm{Ca}^{2+}$ channels in NMDA receptor-independent synaptic plasticity and spatial memory. J. Neurosci., Vol.25, No 43, pp. 9883-92.

Morshita, W., Connor, J. H., Xia, H., Quinlan E, M., Shenolikar, S. \& Malenka R. C. (2001). Regulation of Synaptic Strength by Protein Phosphatase 1. Neuron, Vol.32, pp.1 133-1148.

Mucke, L., Masliah, E., Yu, G. Q., Mallory, M., Rockenstein, E. M., Tatsuno, G., Hu, K., Kholodenko, D., Johnson-Wood, K. \& McConlogue, L. (2000). High-level neuronal expression of A beta 1-42 in wild-type human amyloid protein precursor transgenic mice: synaptotoxicity without plaque formation, J. Neurosci., Vol.20, No.11, pp. 4050-4058, ISSN 0270-6474.

Mulkey, R. M., Herron, C. E. \& Malenka, R. C. (1993). An essential role for protein phosphatases in hippocampal long-term depression. Science, Vol.261, pp. 1051-1055.

Nguyen, P. V. \& Woo, N. H. (2003). Regulation of hippocampal synaptic plasticity by cyclic amp-dependent protein kinases. Prog. Neurobiol., Vol.71, No.6, pp. 401-37.

Nguyen, P. V., Abel, T. \& Kandel, E. R. (1994). Requirement of a critical period of transcription for induction of a late phase of ltp. Science, Vol.265, No.5175, pp. 1104-7.

Nicoll, R. A. \& Schmitz, D. (2005). Synaptic plasticity at hippocampal mossy fibre synapses. Nat. Rev. Neurosci., Vol.6, No.11, pp. 863-76.

Nosyreva, E. D. \& Huber, K. M. (2005). Developmental switch in synaptic mechanisms of hippocampal metabotropic glutamate receptor-dependent long-term depression. J. Neurosci., Vol.25, pp. 2992-3001.

Olds, J., Disterhoft, J. F., Segal, M., Kornblith, C. L. \& Hirsh, R. (1972). Learning centers of rat brain mapped by measuring latencies of conditioned unit responses. $J$. Neurophysiol., Vol.35, No.2, pp. 202. 
O'Leary, H., Liu, W. H., Rorabaugh, J. M., Coultrap, S. J. \& Bayer, K. U. (2011). Nucleotides and phosphorylation bi-directionally modulate $\mathrm{Ca}^{2+} /$ calmodulin-dependent protein kinase II (CaMKII) binding to the N-methyl-D-aspartate (NMDA) receptor subunit GluN2B. J. Biol. Chem. Vol.286, pp. 31272-31281

Omkumar, R. V., Kiely, M., Rosentein, A. J., Min, K. T. \& Kennedy, M. B. (1996). Identification of a phosphorylation site for calcium/calmodulin dependent protein kinase II in the NR2B subunit of the N-methyl-D-aspartate receptor. J. Biol. Chem., Vol.271, pp. 31670-31678

Otmakhov, N., Khibnik, L., Otmakhova, N., Carpenter, S., Riahi, S., Asrican, B. \& Lisman, J. (2004). Forskolin-induced LTP in the ca1 hippocampal region is NMDA receptor dependent. J. Neurophysiol., Vol.91, No.5, pp. 1955-62.

Palop, J. J., Chin, J., Roberson, E. D., Wang, J., Thwin, M. T, Bien-Ly, N., Yoo, J., Ho, K. O., Yu, G. Q, Kreitzer, A., Finkbeiner, S., Noebels, J. L. \& Mucke, L. (2007). Aberrant excitatory neuronal activity and compensatory remodeling of inhibitory hippocampal circuits in mouse models of Alzheimer's disease. Neuron, Vol.55, pp. 697-711.

Palop, J. J. \& Mucke, L. (2010). Amyloid- $\beta$-induced neuronal dysfunction in Alzheimer's disease: from synapses toward neural networks. Nat. Neurosci., Vol.13, No.7, pp. 812- 818.

Park, S., Park, M. J., Kim, S., Kim, J., Shepherd, J. D., Smith- Hicks, C .L., Chowdhury, S., Kaufmann, W., Kuhl, D., Ryazanov, A. G., Huganir, R. L, Linden, D. J. \& Worley, P.F. (2008). Elongation Factor 2 and Fragile X Mental Retardation Protein Control the Dynamic Translation of Arc/Arg3.1 Essential for mGluR-LTD. Neuron, Vol.59, pp. 70-83.

Paz, R. D., Tardito, S., Atzori, M. \& Tseng, K. Y. 2008. Glutamatergic dysfunction in schizophrenia: from basic neuroscience to clinical psychopharmacology. Eur. Neuropsychopharmacol, Vol.18, pp. 773-86.

Pradeep, K. K., Cheriyan, J., Suma Priya, S. D., Rajeevkumar, R., Mayadevi, M., Praseeda, M. \& Omkumar R, V. (2009). Regulation of $\mathrm{Ca}^{2+} /$ calmodulin-dependent protein kinase II catalysis by N-methyl-D-aspartate receptor subunit 2B. Biochem. J., Vol.419, pp. 123-32.

Proctor, D.T., Coulson, E. J. \& Dodd, P. R. (2011). Post-synaptic scaffolding protein interactions with glutamate receptors in synaptic dysfunction and Alzheimer's disease, Progress in Neurobiology, Vol.93, pp. 509-521, ISSN 0301-0082.

Rajeevkumar, R., Suma Priya, S., Mayadevi, M., Mathew Steephan, Santoshkumar ,T. R., John Cheriyan, Sanalkumar, R., Pradeep, K. K., Jackson James \& Omkumar, R. V. (2009). Phosphorylation status of NR2B subunit of NMDA receptor regulates its interaction with Calcium/calmodulin dependent protein kinase II. J. Neurochem., Vol.110, pp. 92-105.

Ramnani, N. (2006). The primate cortico-cerebellar system: anatomy and function. Nat. Rev. Neurosci., Vol.7, pp. 511-522.

Raymond, C. R. (2008). Different requirements for action potentials in the induction of different forms of long-term potentiation. J. Physiol, Vol.586, No.7, pp. 1859-65. 
Reymann, K. G. \& Frey, J. U. (2007). The late maintenance of hippocampal LTP: Requirements, phases, 'synaptic tagging', 'late-associativity' and implications. Neuropharmacology, Vol.52, No.1, pp. 24-40.

Roberson, E. D., Halabisky, B., Jong, W., Yoo., Yao, J., Chin, J., Yan, F., Wu, T., Hamto, P., Devidze, N., Yu, G., Palop, J. J., Noebels, J. L. \& Mucke, L. (2011). Amyloid- $\beta /$ Fyninduced synaptic, network, and cognitive impairments depend on tau levels in multiple mouse, models of Alzheimer's disease, The Journal of Neuroscience, Vol.31, No.2, pp. 700 -711, ISSN 0270-6474.

Rygh, L, J., Svendsen, F., Fiska, A., Haugan, F., Hole, K. \& Tjølsen, A. (2005). Long-term potentiation in spinal nociceptive systems - how acute pain may become chronic. Psychoneuroendocrinology, Vol.30, pp. 959-964.

Schonewille, M., Gao, Z., Henk-Jan Boele., Vinueza Veloz M, F., Amerika W, E., Simek A. A. M., De Jeu, M. T., Steinberg, J. P., Takamiya, K., Hoebeek, F. E., Linden, D. J,. Huganir, R. L. \& De Zeeuw, C. I. (2011). Reevaluating the Role of LTD in Cerebellar Motor Learning, Neuron, Vol.70, pp. 43-50.

Scoville, W. B. \& Milner, B. (1957). Loss of recent memory after bilateral hippocampal lesions. Journal of Neurology, Neurosurgery \& Psychiatry, Vol.20, No.1, pp. 11.

Selkoe, D. J. (2008). Soluble oligomers of the amyloid beta-protein impair synaptic plasticity and behavior. Behav. Brain Res., Vol.192, pp. 106-113, ISSN 0166-4328.

Sgobio, C., Ghiglieri, V., Cinzia Costa, C., Bagetta, V., Siliquini, S., Barone, I.,Filippo, M., Gardoni, F., Gundelfinger, E. D., Di Luca, M., Picconi, B. \& Calabresi, P. (2010). Hippocampal synaptic plasticity, memory, and epilepsy: Effects of long-term valproic acid treatment, Biol. Psychiatry., Vol.67, pp. 567-574, ISSN 0006-3223.

Shankar, G. M., Bloodgood, B. L., Townsend, M., Walsh, D. M., Selkoe, D. J. \& Sabatini, B. L (2007). Natural oligomers of the Alzheimer amyloid-beta protein induce reversible synapse loss by modulating an NMDA-type glutamate receptor-dependent signaling pathway. J. Neurosci., Vol.27, pp. 2866-2875, ISSN 0270-6474.

Shankar, G. M., Li, S., Mehta, T. H., Garcia-Munoz, A., Shepardson, N. E., Smith, I., Brett, F. M., Farrell, M. A., Rowan M. J. \& Lemere C. A. (2008). Amyloid- protein dimers isolated directly from Alzheimer's brains impair synaptic plasticity and memory. Nature medicine, Vol.14, pp. 837-842.

Shepherd, J. D. \& Bear, M. F. (2011). New views of Arc, a master regulator of synaptic plasticity, Nature Neuroscience, Vol.14, No.3, pp. 279-284.

Shipton, O. A., Leitz, J. R., Dworzak, J., Christine, E. J. Acton,C. E., Tunbridge, E. M., Denk, F., Hana, N., Dawson, H. N, Vitek, M. P, Wade-Martins, R., Paulsen, O. \& VargasCaballero, M. (2011). Tau protein is required for amyloid $\beta$-induced impairment of hippocampal long-term potentiation, J. Neurosci, Vol.31, No.5, pp. 1688 -1692, ISSN 0270-6474.

Smith, C. C. \& Mcmahon, L. L. (2005). Estrogen-induced increase in the magnitude of longterm potentiation occurs only when the ratio of NMDA transmission to AMPA transmission is increased. J. Neurosci, Vol.25, No.34, pp. 7780-91.

Snyder, E. M., Philpot, B. D., Huber, K. M.,Dong, X., Fallon, J. R., \& Bear, M. F. (2001). Internalization of ionotropic glutamate receptors in response to mGluR activation. Nat. Neurosci., Vol.4. pp. 1079-1085. 
Stephan, A., Laroche, S. \& Davis, S. (2001). Generation of aggregated b-Amyloid in the rat hippocampus impairs synaptic transmission and plasticity and causes memory deficits, J. Neurosci, Vol.21, No.15, pp. 5703-5714.

Strack, S., McNeill R. B \& Colbran, R. J. (2000). Mechanism and regulation of calcium/calmodulin dependent protein kinase II targeting to the NR2B subunit of the N-methyl-D-aspartate receptor. J. Biol. chem., Vol.273, pp. 23789-23806.

Sweatt, J. D. (2010). Mechanisms of memory. Academic press, U.K., 2 nd Edition, ISBN 978-012374951-2.

Tackenberg, C. \& Brandt, R. (2009). Divergent pathways mediate spine alterations and cell death induced by amyloid- $\beta$, wild-type tau, and R406W tau, J. Neurosci., Vol.29, No.46, pp. 14439 -14450, ISSN 0270-6474/09/291443.

Tergau, F., Naumann, U., Paulus, W. \& Steinhoff, B. J. (1999). Low-frequency repetitive transcranial magnetic stimulation improves intractable epilepsy. Lancet, Vol.353, pp. 2209.

Teyler, T. J. \& Discenna, P. (1987). Long-term potentiation. Annu Rev Neurosci, Vol.10, pp. 131-61.

Tiron ,A. \& Wibrand, K. (2010). The Arc of synaptic memory. Exp. Brain Res., Vol.200, pp. 125-140.

Ueda, K., Shinohara, S., Yagami, T., Asakura, K. \& Kawasaki, K. (1997). Amyloid beta protein potentiates $\mathrm{Ca}{ }^{2+}$ influx through L-type voltage-sensitive $\mathrm{Ca}^{2+}$ channels: A possible involvement of free radicals. J. Neurochem., Vol.68, pp. 265-271.

Vogt, K. E. \& Canepari, M. (2010). On the Induction of Postsynaptic Granule Cell - Purkinje Neuron LTP and LTD. The Cerebellum, Vol.9, No.3, pp. 284-90.

Walsh, D. M., Klyubin, I., Fadeeva, J. V., Cullen, W. K., Anwyl, R., Wolfe, M. S, Rowan, M. J. \& Selkoe, D. J. (2002). Naturally secreted oligomers of amyloid $\beta$ protein potently inhibit hippocampal long-term potentiation in vivo, Nature, Vol.416, pp. 535-539.

Wang, H. W., Pasternak, J. F., Kuo, H., Ristic, H., Lambert, M. P., Chromy, B., Viola, K. L., Klein, W. L., Stine, W. B., Krafft, G. A. \& Trommer, B. L. (2002). Soluble oligomers of beta amyloid (1-42) inhibit long-term potentiation but not long-term depression in rat dentate gyrus, Brain Res., Vol.924, No.2, pp. 133-140, ISSN 0006-8993.

Wang, Q., Rowan, M. J. \& Anwy, 1. R. (2004). Beta-amyloid-mediated inhibition of NMDA receptor-dependent long-term potentiation induction involves activation of microglia and stimulation of inducible nitric oxide synthase and superoxide. J. Neurosci., Vol.24, No.27, pp. 6049-6056, ISSN 0270-6474/04/246049-08.

West, A. E., Chen, W. G., Dalva, M. B., Dolmetsch, R. E., Kornhauser, J. M., Shaywitz, A. J., Takasu, M. A., Tao, X. \& Greenberg, M. E. (2001). Calcium regulation of neuronal gene expression. Proc. Natl. Acad. Sci. USA., Vol.98, No.20, pp. 11024-31.

Williams, J. H., Errington, M. L., Lynch, M. A. \& Bliss, T. V. (1989). Arachidonic acid induces a long-term activity-dependent enhancement of synaptic transmission in the hippocampus. Nature, Vol.341, No.6244, pp. 739-42.

Woo, N. H., Teng, H. K., Siao, C. J., Chiaruttini, C., Pang, P. T ., Milner, T. A., Hempstead, B. L. \& Bai Lu. (2005). Activation of p75NTR by proBDNF facilitates hippocampal long-term depression. Nature Neuroscience, Vol.8, pp. 1069 - 1077. 
Wyneken, U., Marengo, J. J., Villanueva, S., Soto, D. Sandoval, R. Gundelfinger, E. D. \& Orrego, F. (2003). Epilepsy-induced changes in signaling systems of human and rat postsynaptic densities, Epilepsia, Vol.44, No.2, pp. 243-246.

Xia, W. (2010). Brain amyloid $\beta$ protein and memory disruption in Alzheimer's disease, Neuropsychiatric Disease and Treatment, Vol.6, pp. 605-612.

Xia, J., Chung, H. J., Wihler, C., Huganir, R. L. \& Linden, D. J. (2000). Cerebellar long term depression requires PKC-regulated interactions between GluR2/3 and PDZ domain containing proteins. Neuron, Vol.28, pp. 499-510.

Yasuda, H., Barth, A. L., Stellwagen, D. \& Malenka, R. C. (2003). A developmental switch in the signaling cascades for LTP induction. Nat Neurosci, Vol.6, No.1, pp. 15-6.

Zeng, Y., Zhao, D. \& Xie, C. W. (2010). Neurotrophins enhance CaMKII activity and rescue amyloid-beta induced deficits in hippocampal synaptic plasticity. J. Alzheimers Dis., Vol.21, No.3, pp. 823-831.

Zukin R. S., Richter J. D. \& Bagni, C. (2009) Signals, synapses and synthesis: how new proteins control plasticity. Frontiers in neural circuits, Vol.3, No.14, pp. 1-8. 


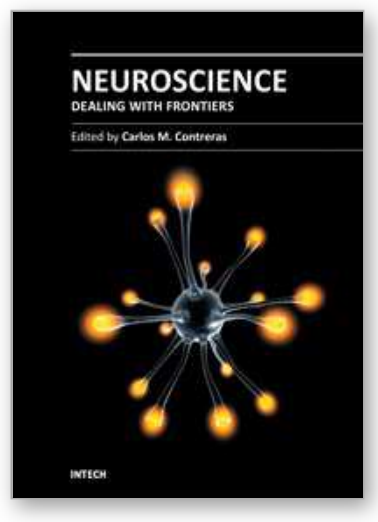

\author{
Neuroscience - Dealing With Frontiers \\ Edited by Dr. Carlos M. Contreras
}

ISBN 978-953-51-0207-6

Hard cover, 440 pages

Publisher InTech

Published online 16, March, 2012

Published in print edition March, 2012

The Neuronal Doctrine recently reached its 100th year and together with the development of psychopharmacology by the middle of 20th century promoted spectacular developments in the knowledge of the biological bases of behavior. The overwhelming amount of data accumulated, forced the division of neuroscience into several subdisciplines, but this division needs to dissolve in the 21 st century and focus on specific processes that involve diverse methodological and theoretical approaches. The chapters contained in this book illustrate that neuroscience converges in the search for sound answers to several questions, including the pathways followed by cells, how individuals communicate with each other, inflammation, learning and memory, the development of drug dependence, and approaches to explaining the processes that underlie two highly incapacitating chronic degenerative illnesses.

\title{
How to reference
}

In order to correctly reference this scholarly work, feel free to copy and paste the following:

M. Mayadevi, G.M. Archana, Ramya R. Prabhu and R.V. Omkumar (2012). Molecular Mechanisms in Synaptic Plasticity, Neuroscience - Dealing With Frontiers, Dr. Carlos M. Contreras (Ed.), ISBN: 978-953-51-0207-6, InTech, Available from: http://www.intechopen.com/books/neuroscience-dealing-with-frontiers/molecularmechanisms-in-synaptic-plasticity

\section{INTECH}

open science | open minds

\author{
InTech Europe \\ University Campus STeP Ri \\ Slavka Krautzeka 83/A \\ 51000 Rijeka, Croatia \\ Phone: +385 (51) 770447 \\ Fax: +385 (51) 686166 \\ www.intechopen.com
}

\author{
InTech China \\ Unit 405, Office Block, Hotel Equatorial Shanghai \\ No.65, Yan An Road (West), Shanghai, 200040, China \\ 中国上海市延安西路65号上海国际贵都大饭店办公楼 405 单元 \\ Phone: +86-21-62489820 \\ Fax: +86-21-62489821
}


(C) 2012 The Author(s). Licensee IntechOpen. This is an open access article distributed under the terms of the Creative Commons Attribution 3.0 License, which permits unrestricted use, distribution, and reproduction in any medium, provided the original work is properly cited. 